Nonlinear Processes in Geophysics, 12, 537-555, 2005

SRef-ID: $1607-7946 / \mathrm{npg} / 2005-12-537$

European Geosciences Union

(C) 2005 Author(s). This work is licensed

under a Creative Commons License.

\title{
Evaluation of Eta Model seasonal precipitation forecasts over South America
}

\author{
S. C. Chou, J. F. Bustamante, and J. L. Gomes \\ Center for Weather Prediction and Climate Studies - CPTEC, National Institute for Space Research, INPE, Brazil \\ Received: 5 November 2004 - Revised: 7 April 2005 - Accepted: 10 May 2005 - Published: 3 June 2005 \\ Part of Special Issue "Quantifying predictability"
}

\begin{abstract}
Seasonal forecasts run by the Eta Model over South America were evaluated with respect to precipitation predictability at different time scales, seasonal, monthly and weekly for one-year period runs. The model domain was configured over most of South America in $40 \mathrm{~km}$ horizontal resolution and 38 layers. The lateral boundary conditions were taken from CPTEC GCM forecasts at T62L28. The sea surface temperature was updated daily with persisted anomaly during the integrations. The total time integration

ity was evaluated by tracking the frontal passages along the eastern coast. The frontal timing was no longer captured by the model but some indication of the frequency and of the northward movement was given by the model forecast. Weekly precipitation totals were evaluated for the São Francisco Basin. Some parameters, such as the mean and the standard deviation of the 7-day total precipitation, were comparable to observations. The correlations between the forecast and the observed 7-day series were positive, but low.
\end{abstract} length was 4.5 months. The Eta seasonal forecasts represented reasonably well the large scale precipitation systems over South America such as the Intertropical Convergence Zone and the South Atlantic Convergence Zone. The total amounts were comparable to observations. The season total precipitation forecasts from the driver model exhibited large overestimate. In general, the largest precipitation errors were found in ASON season and the smallest in FMAM. The major error areas were located along the northern and northeastern coast and over the Andes. These areas were present in both models. The monthly precipitation totals indicated that the intra-seasonal variability, such as the monsoonal onset, was reasonably captured by the model. The equitable threat score and the bias score showed that the Eta Model forecasts had higher precipitation predictability over the Amazon Region and lower over Northeast Brazil. The evaluation of the precipitation forecast range showed that at the fourth month the forecast skill was still comparable to the first month of integration. Comparisons with the CPTEC GCM forecasts showed that the Eta improved considerably the forecasts from the driver model. Five-member ensemble runs were produced for the NDJF rainy season. Both driver model and Eta Model forecasts showed some internal variability in the SACZ and over the Andes regions. Comparison of the Eta Model seasonal forecasts against climatology showed that in general the model produced additional useful information over the climatology. Transient variabil-

Correspondence to: S. C. Chou

(chou@cptec.inpe.br)

\section{Introduction}

The importance of seasonal forecasts in various fields such as agriculture, hydrology, economy is unquestionable. Planning ahead the activities, choosing the appropriate culture, optimizing the control of reservoirs and energy consumption can yield considerable reduction of losses and even large profit. This would be the ideal case if it were not for the forecast errors and the uncertainties in the current seasonal forecasts.

The misuse and misinterpretation of seasonal forecast products can limit the use of regional climate forecasts as a tool to seasonal predictions. Various uncertainties involve regional climate modeling. It is intuitive that integrations using analyses along the lateral boundaries of the regional model could give better results than using forecasts. The analyses are closer to observations, while the forecasts carry the errors of the driver model. Druyan et al. (2002) performed experiments with GISS/Regional Climate Model (RCM) over Brazil using persisted and observed SST anomalies during rainy seasons of March-April-May of 1985 and 1997 at $0.5^{\circ}$ resolution. They used both the GISS/General Circulation Model (GCM) and the National Centers for Environmental Prediction (NCEP) reanalyses as lateral boundary conditions. Their results showed, however, the difficulty for the model in capturing the realistic precipitation distribution even using actual climate data as lateral and lower boundary conditions.

The increase of horizontal resolution is also expected to improve the regional model results. In Nobre et al. (2001) 
the nesting of Regional Spectral Model at $80 \mathrm{~km}$ resolution improved the downscaling of the ECHAM3 GCM to simulate rains over Northeast Brazil during the rainy season, from January until April 1999, however, at $20 \mathrm{~km}$, the results became poorer than with $80 \mathrm{~km}$ version.

There is a variety of problems related to growth of model error in longer integrations. Different models show different error behaviors. Chou et al. (2000) performed extended range forecasts using Eta Model at $80 \mathrm{~km}$ horizontal resolution and using CPTEC GCM as lateral boundary conditions. Although the model had the simple bucket surface scheme, a considerable improvement of precipitation over the GCM simulation, which used $\mathrm{SSiB}$ surface scheme, was obtained for both rainy and dry months.

Predictability at seasonal scale should be controlled by large scale slow variability and lower boundary conditions played by sea surface temperature (SST) and soil moisture. Based on GCM results, it has been shown that the precipitation and circulation variability over Northeast Brazil is associated with the SST variability over the Tropical Atlantic Ocean (Moura and Shukla, 1986). The upper limit of predictability is obtained by constraining the simulations to observed SST (Palmer et al., 1990). In limited area climate modeling, however, predictability may also have dependency on the lateral boundary conditions. Laprise et al. (2000) used the Canadian Regional Climate Model and found no predictability in scales finer than the lateral boundary forcing. They supported stronger surface forcing in a limited area model for adding predictability to finer scales in extended range simulations. However, Chou et al. (2003) showed that in the regional Eta Model configured over South America, the sea surface temperature played smaller role in configuring the large scale circulation pattern in the regional model domain, but rather the lateral boundary conditions played the major role.

In Druyan et al. (2002) the regional simulations produced a more stable lower-troposphere compared to the lateral boundary forcing conditions. Their results showed that the errors from the large scale boundary forcing are not necessarily transferred into the regional simulations.

In the predictability study carried out by Misra (2003), the COLA AGCM was run in two modes: continuous multiannual runs and 3.5-months run. The integrations showed that model errors have different magnitudes at different time scales, the seasonal runs outperforms the multi-annual runs, except over Northeast Brazil where smaller errors in multiannual runs were found. Opposite precipitation error signs could also be noticed over Northern Brazil.

There should be some efforts on evaluating the predictability and identifying the model errors, so that the currently available forecasts can be applied more adequately and errors can be reduced or corrected. The works described above show that some limited area climate modeling experience should not be generalized to all model configurations. The objective of the present work is to assess the predictability of seasonal precipitation over South America using the Eta Model for one year period. Predictability will be evaluated for different forecast ranges, from seasonal to weekly scale, in order to identify the usefulness of precipitation forecasts at longer integration ranges. Objective and pattern evaluations of precipitation forecasts will be carried out. Comparisons with the driver model forecasts are included. One season ensemble is attempted for assessing model internal variability. The model configuration is described in Sect. 2. The seasonal integration and the evaluation methodology is explained in Sect. 3. The results are in Sect. 4. Finally, the discussion and conclusions are drawn in Sect. 5.

\section{Model configuration}

The Eta Model resolution was $40 \mathrm{~km}$ in horizontal and 38 layers in the vertical. The domain covered most of South America and part of adjacent oceans. The model equations are expressed in the $\eta$ coordinate, defined as (Mesinger, 1984).

$\eta=\frac{p-p_{t}}{p_{s}-p_{t}} \frac{p_{r}\left(z_{s}\right)-p_{t}}{p_{r}(0)-p_{t}}$

where $p$ is the air pressure and $z$ is the height. The indices $t$ and $s$ indicate model top and model surface, respectively. The index $r$ refers to values from a reference atmosphere, therefore, $p_{r}(0)$ is the air pressure at the height 0 , and $p_{r}\left(z_{s}\right)$ is the air pressure at the surface,with both pressures taken from a reference atmosphere. Because the surfaces of the coordinate are approximately horizontal, this feature is particularly useful for regions with steep orography such as South America because of the presence of the Andes Cordillera.

The time scheme applied is the forward-backward scheme for the adjustment terms and first-forward-then-uncentered scheme for the horizontal advection. The space difference scheme suppresses the two C-subgrid gravity wave separation (Mesinger, 1974; Janjic, 1979). Lateral boundary conditions are prescribed along a single outer line without need for boundary relaxation (Mesinger, 1977). The prognostic variables are temperature, specific humidity, horizontal wind, surface pressure, the turbulent kinetic energy and cloud liquid water/ice. These variables are distributed on the Arakawa type E-grid.

The model uses Betts-Miller scheme (Janjic, 1994) to produce convective precipitation. Stable precipitation is produced explicitly through Zhao cloud scheme (Zhao and Carr, 1997). The surface hydrology is solved by Chen scheme (Chen et al., 1997). This scheme distinguishes 12 types of vegetation and 7 types of soil texture. The radiation scheme package was developed by the Geophysical Fluid Dynamics Laboratory. The scheme includes short-wave (Lacis and Hansen, 1974) and long-wave radiation (Fels and Schwarzkopf, 1975). The radiation tendencies are updated every $1 \mathrm{~h}$.

Initial soil moisture is derived from a monthly climatology, while the albedo starts from a seasonal climatology. The initial atmospheric conditions are taken from NCEP analyses. 
Because the goal is to evaluate the skill for forecasting precipitation at different time ranges, the lateral boundary conditions are taken from forecasts. The CPTEC global model forecasts (Bonatti, 1996; Cavalcanti et al., 2002) are input as lateral boundary conditions. The latter conditions are updated every $6 \mathrm{~h}$ at the boundaries. The tendencies at these boundaries are kept constant within the 6-h interval and applied along the single outermost line of the model domain (Mesinger, 1977).

The CPTEC GCM (Bonatti, 1996; Cavalcanti et al., 2002) is a spectral model with triangular truncation and uses sigma vertical coordinates. The convective precipitation is produced by the Kuo scheme (Kuo, 1974) and the large scale condensation is produced by the NCEP scheme (NMC, 1988). The short wave radiation is based on the Lacis and Hansen scheme (Lacis and Hansen, 1974), whereas the longwave radiation is based on Harshvardhan et al. (1974). Planetary Boundary Layer vertical turbulence follows MellorYamada level 2.0 scheme (Mellor and Yamada, 1982). The land surface scheme is based on the SSiB scheme (Simplified Simple Biosphere Model) (Xue et al., 1991).

\section{Methodology}

For climate applications, the atmospheric model forecasts were evaluated based on mean values taken over a time range. In this work, the skill of the forecasts was evaluated for seasonal, monthly, and seven-day means. The patterns of the precipitation forecasts were evaluated for 4 seasons referred to as FMAM for the period from February to May 2002, MJJA for the period from May to August 2002, ASON for the period from August to November 2002, and NDJF for the period from November 2002 to February 2003. NDJF is the rainy season over the central part of South America, FMAM is a transition period toward the dry season, MJJA is the dry season over the central part of the continent, and ASON is the transition period toward the rainy season. The FMAM is the important period for rains over Northeast Brazil and the northern part of the Amazon region.

Twelve 4.5 month integrations were performed, using both the CPTEC GCM and the Eta Model. All the 12 integrations started on the day 15 of each month of the year. A 15day model spin-up period was considered for both models. The forecasts from spin-up period were discarded. The initial conditions were taken from NCEP analyses at T062L28 resolution for both regional and global models. The lateral boundaries of the Eta Model were updated every $6 \mathrm{~h}$ from the CPTEC GCM forecasts at T062L28 resolution. Observed SST was taken on the first day of integration and it was daily updated by persisting the anomaly of the first day of integration. The same persisted SST were used for both the CPTEC GCM and the Eta model.

Quantitative precipitation evaluation was based on the equitable threat score and the bias score. These scores evaluated the twelve seasonal runs of the year and were based on monthly total precipitation values. Correlation between (a)

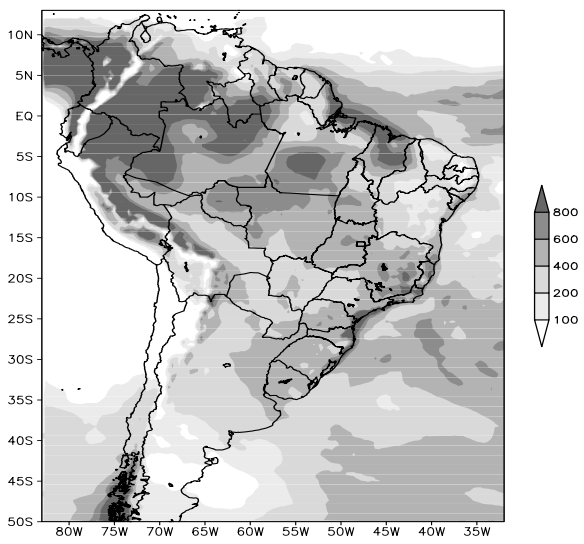

(b)

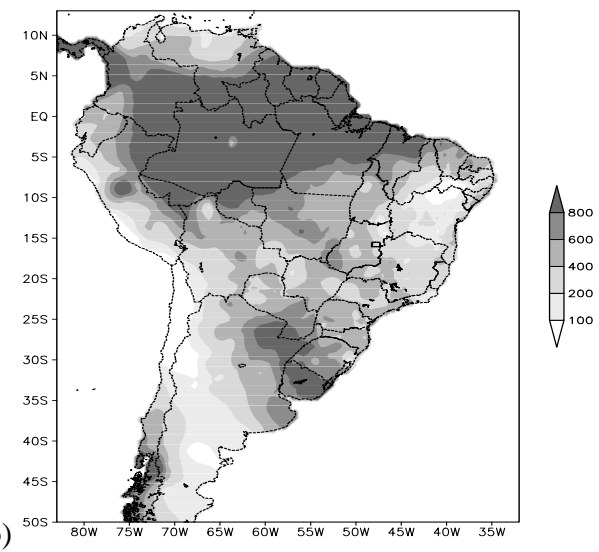

Fig. 1. FMAM season total precipitation (mm): (a) Eta Model forecast, (b) Observation.

forecast and observed precipitation was obtained. Precipitation was evaluated against surface observations and, therefore, limited to continental area. The spatial distribution of surface stations is very irregular throughout South America.

\section{Results}

\subsection{Seasonal total precipitation}

FMAM is the rainy season of the central part of the Amazon region. Figure 1a shows the predicted FMAM season total precipitation from a forecast which was initialized on 15 January 2002. Precipitation total exceeded $800 \mathrm{~mm}$ in some areas. The Inter-tropical Convergence Zone has substantial influence on the precipitation of this region. In addition, organized convective lines form along the northern coast and propagate inland toward central Amazonia (Garstang et al., 1994). The lack of structure in the observed precipitation field in the Amazon region may be partially due to the precipitation analyses taken from a relatively small amount of observation stations available (Fig. 1b). The model produced a more structured precipitation along the northern coast, where the model tended to overestimate the rains, whereas in the southern part of Brazil, the model underestimated them. The precipitation bands related to the South Atlantic 
(a)

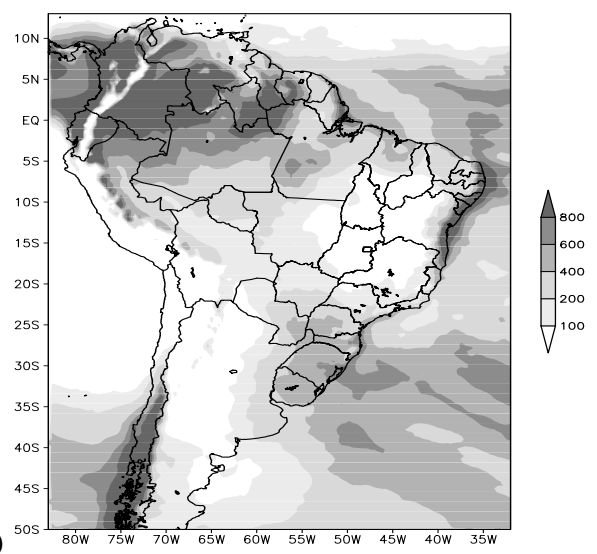

(b)

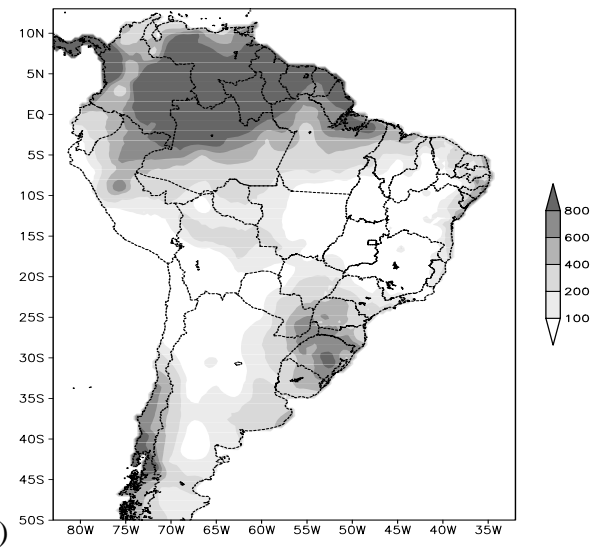

Fig. 2. MJJA season total precipitation (mm): (a) Eta Model forecast, (b) Observation.

Convergence Zone seem to have advanced further north compared to observations, which showed maximum precipitation in Southern Brazil.

MJJA is the dry season. The model describes correctly the cloud free regions in the central part of Brazil (Fig. 2). The predicted season total precipitation showed a region of minimum values near the northern coast, around $0^{\circ} \mathrm{S}$ and $60^{\circ} \mathrm{W}$, between the States of Pará and Amapá in Brazil, which is not shown in the surface observations. Along the eastern coast, the model strongly overestimated the precipitation, although some precipitation was observed near the easternmost coast, the model extended this precipitation feature to the south. The narrow precipitation area in the Southern part of Chile was captured by the model, but it overestimated the amount.

The ASON contains the onset of the South America monsoonal system. The precipitation usually begins in the middle of this season. The forecasts (Fig. 3) capture the return of the rains during this season similar to the observations. The rains along the eastern coast were again overestimated. The rains in the southern part of Brazil were correctly forecast by the model.

The NDJF total precipitation forecast by the model agrees well with the observed total precipitation (Fig. 4). This is the main rainy season for the central part of the continent. Convection can be organized in large scale band referred to

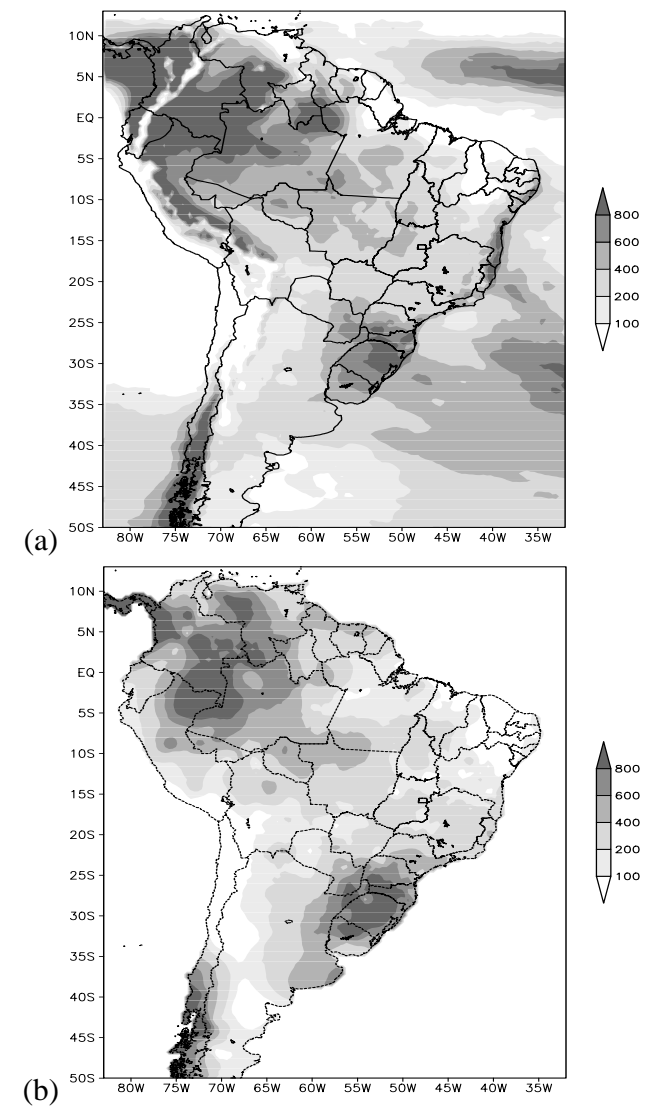

Fig. 3. ASON season total precipitation (mm): (a) Eta Model forecast, (b) Observation.

as the South Atlantic Convergence Zone (SACZ). Some areas of precipitation maxima, such as in the Rondônia State, south of state of Pará and central part of Brazil were predicted by the model, although it underestimated the precipitation values. The localized heavy convective precipitation events are generally underestimated and sometimes missed in daily weather forecasts, in seasonal forecast these errors are accumulated and become more evident. In the south and southeast regions of Brazil, the magnitude of the rains about $600 \mathrm{~mm}$ were reasonably forecast by the model. The rains along the northern coast, however, were missed by the model.

The model captured the general pattern of the 4-month total precipitation. The magnitude of the total precipitation was comparable to observations. Three areas of disagreement can be identified: near the northern coast between the states of Pará and Amapá, along the eastern coast of Northeast Brazil and in the southern part of Chile. Some excessive rain can be found near these coastal regions, mainly in FMAM and MJJA. This excessive precipitation seems to be partly caused by the convective parametrization scheme which in the version used adopts different reference profiles for the sea and the land points and causes larger contrasts. The excessive rain along the coast can also be partly due to the stronger winds produced when CPTEC GCM is used as lateral boundary conditions. Figure 5 shows the $850-\mathrm{hPa}$ winds averaged 
(a)
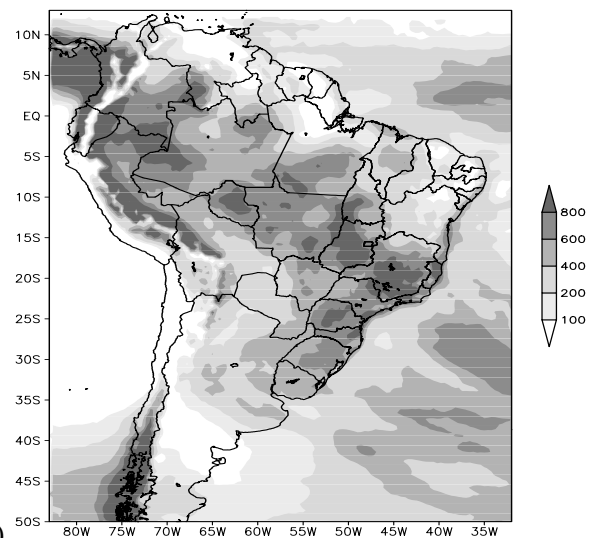

(b)

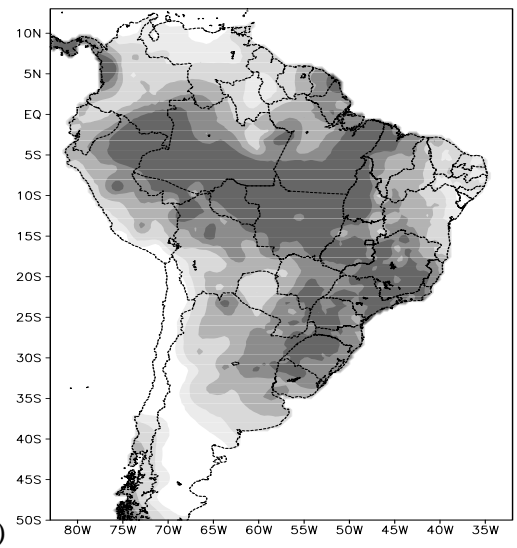

Fig. 4. NDJF season total precipitation (mm): (a) Eta Model forecast, (b) Observation.

over the MJJA months. Along the coastline, between $12^{\circ} \mathrm{S}$ and $20^{\circ} \mathrm{S}$, the CPTEC GCM winds are stronger than the analyses winds and they also hit the coast in more perpendicular direction. Tests using NCEP analyses as lateral boundary do not show the excessive rain along the coast.

Figures $6 \mathrm{a}-\mathrm{d}$ show the season total precipitation forecasts from the driver model, the CPTEC GCM. In FMAM the precipitation band across the continent was more positioned toward the Northeast of Brazil than shown in the observations (Fig. 1b). The precipitation values were also larger. A maximum of precipitation in the region that encompasses northeast of Argentina, Uruguay and southern Brazil seemed to be positioned to the south, but underestimated by both GCM and Eta Model. In MJJA, the excessive precipitation along the eastern coast of Northeast Brazil is also present in the driver model. This excessive rain extended to the northern coast of Northeast Brazil different from the Eta forecast. The position of the rains in southern Brazil were better forecast, although the amounts were underestimated by the GCM and Eta Model. In the ASON, the CPTEC GCM continued to overestimate the rains along the eastern coast. This feature was also present in the Eta forecast, but less evident. The rains over the Amazon and southern Brazil were forecast by both models. In the rainy season, NDJF, the CPTEC GCM captured the major precipitation areas over the continent.

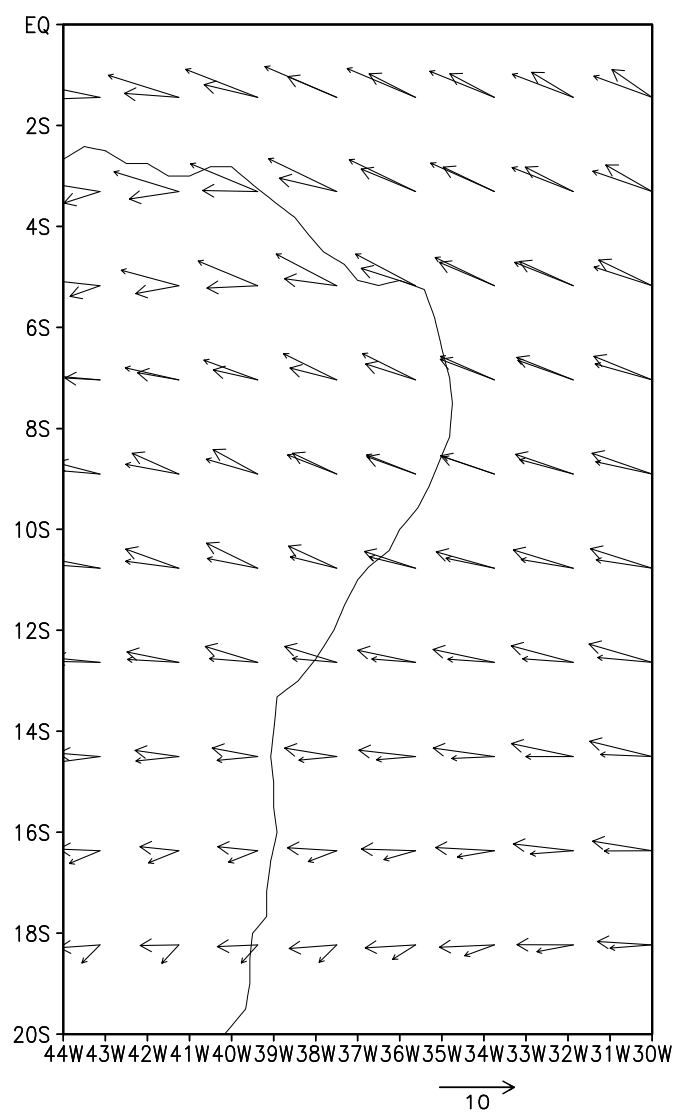

Fig. 5. MJJA mean $850-\mathrm{hPa}$ winds from the NCEP analyses (small arrow head) and the CPTEC GCM run (large arrow head).

The CPTEC GCM generally produced more precipitation than the Eta model. Although the CPTEC GCM captured the general pattern of the precipitation forecasts, the comparison with the Eta forecasts shows a considerable improvement of the Eta Model over the GCM. The maximum of rain over the Bolivian Highlands occurred in most seasons. The verification with satelite images revealed that this feature is not present in observations and represents a model systematic error. This error feature is not present in the Eta forecasts.

\subsection{NDJF season ensemble forecasts}

In order to extend the assessment of the seasonal precipitation forecast skill, an ensemble of forecasts were carried out for the rainy season, NDJF 2002-2003. The ensemble was produced with runs using the CPTEC GCM forcing starting on 5 different days: 13, 14, 15, 16 and 17 October 2002. The Eta runs started on the same dates. The ensemble mean of the total season precipitation are shown in Fig. 7 for both Eta Model and CPTEC GCM.

The precipitation patterns of the ensemble runs are very similar to the patterns from the deterministic runs of both Eta Model and CPTEC GCM shown in Figs. 4d and 6d. The position of the major precipitation band across the continent, the SACZ, and the magnitude of the maximum values 


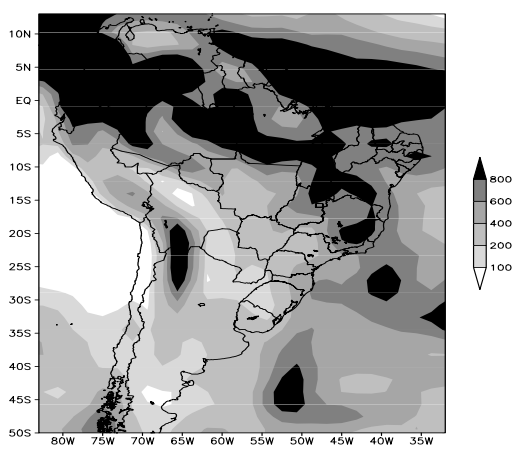

(a)

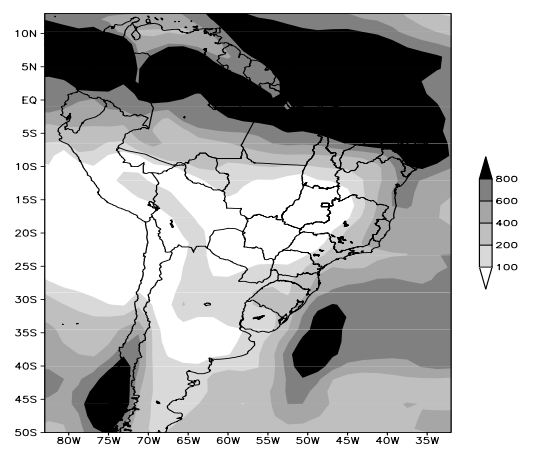

(b)

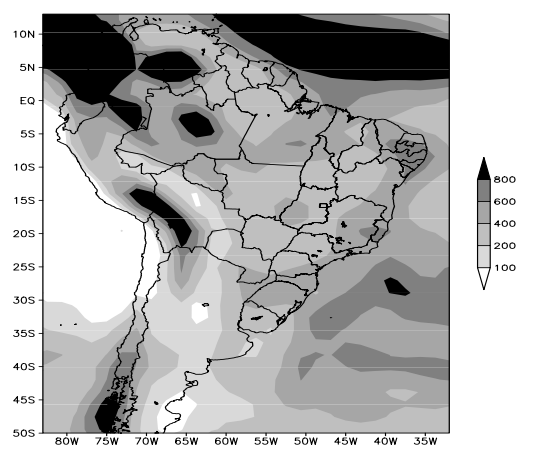

(c)

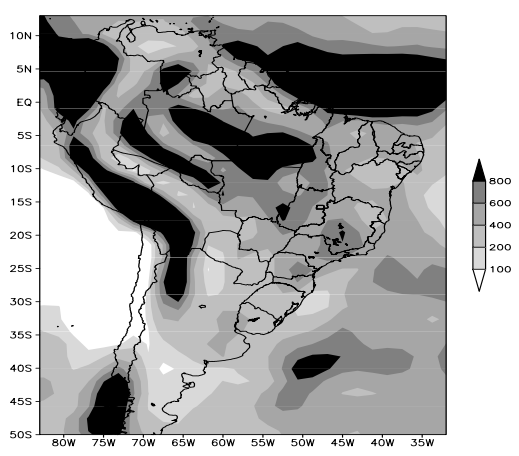

(d)

Fig. 6. CPTEC GCM season total precipitation forecast (mm): (a) FMAM, (b) MJJA, (c) ASON and (d) NDJF.
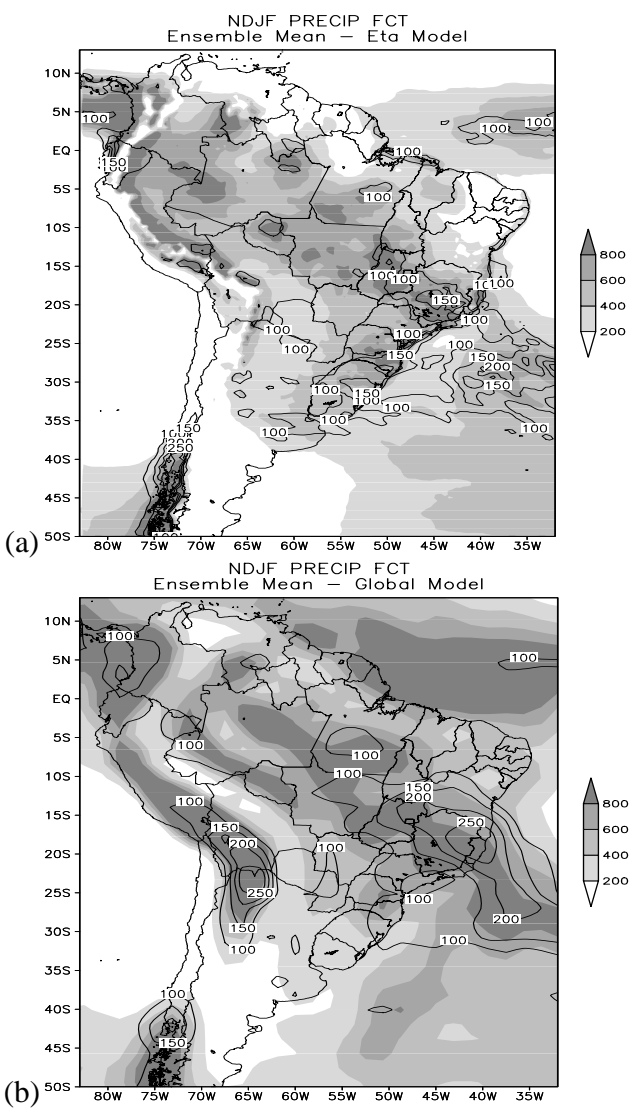

Fig. 7. Ensemble mean of NDJF season total precipitation (shading) and the spread among the members (contour): (a) Eta Model and (b) CPTEC GCM. The spread was calculated from the daily total precipitation and the magnitude was converted to seasonal value. Only spread values above $100 \mathrm{~mm}$ are indicated.

of precipitation of the ensemble runs are also very similar to the single runs. These similarities indicate that both models have small internal variability. At seasonal ranges, part of the internal variability of the regional model comes from the lateral boundary conditions. The spread among the members was measured by the standard deviation of the daily total precipitation forecasts. Both models showed largest variability in the regions related to the SACZ activity, over the continent near the coastal areas and over the Atlantic Ocean. The large spread over the Bolivian Highlands in the GCM precipitation forecasts did not occur in the Eta Model. The Eta Model showed the largest spread over the Andes, south of $40^{\circ} \mathrm{S}$. The few observations present in this region showed that both models overestimated the rains. More observations would be necessary in order to identify the model error sources.

\subsection{Monthly total precipitation}

The seasonal forecasts are evaluated in monthly total precipitation. The forecast and observed precipitation for each season are shown in Figs. 8-11. The discussion that follows refer to monthly results from each 4 of the 4 -month forecasts. 
(a)

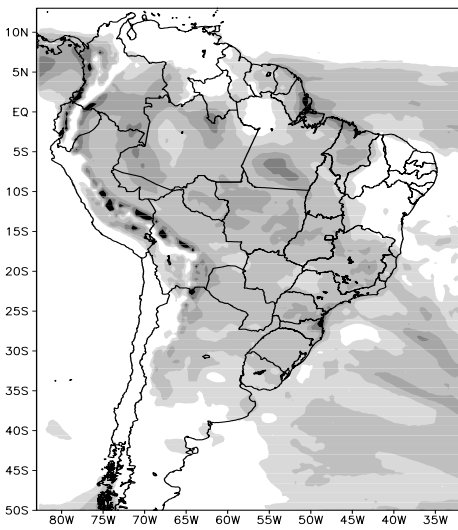

(d)

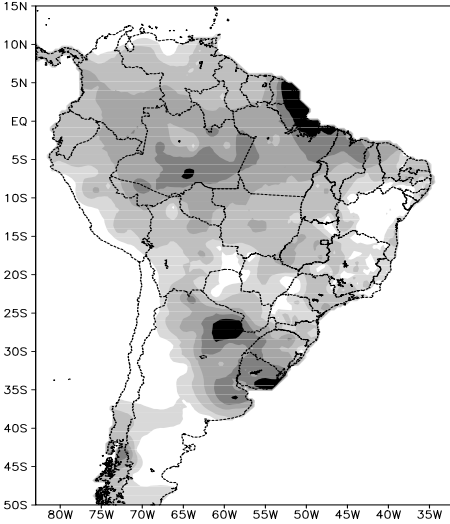

(g)

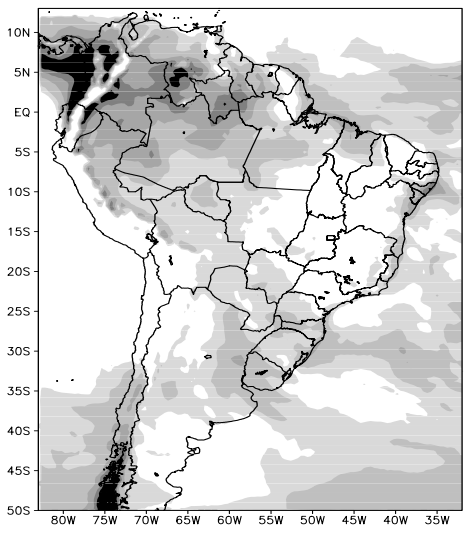

(b)
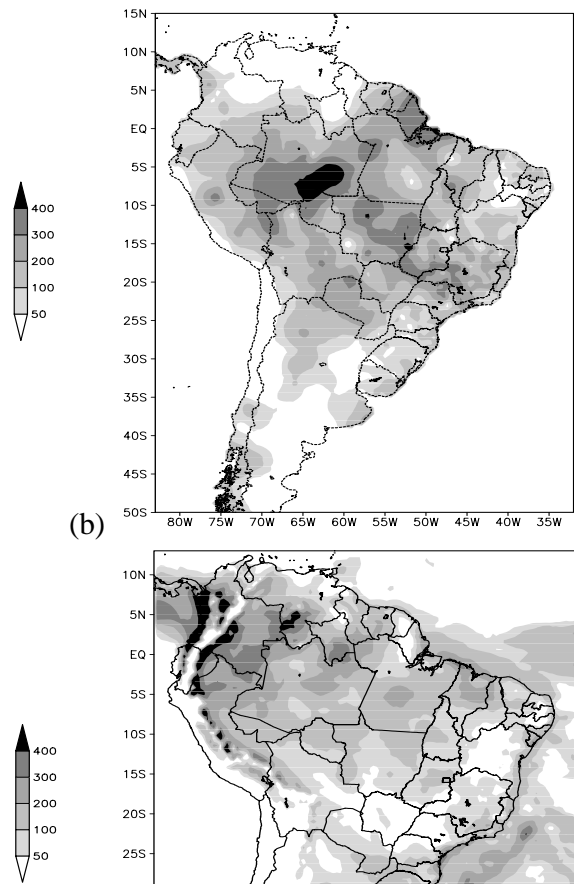

(e)

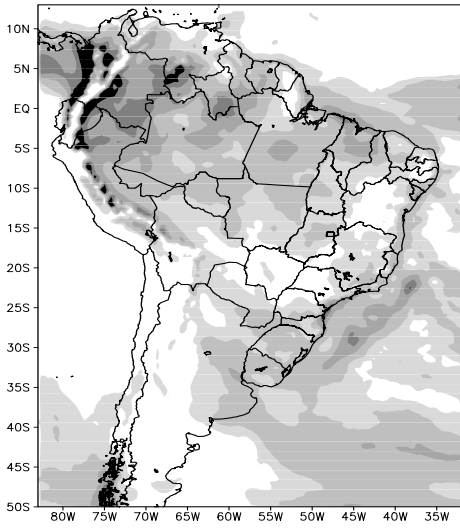

$A^{400}$
300
3200
$H_{50}$
500

(f)

(c)
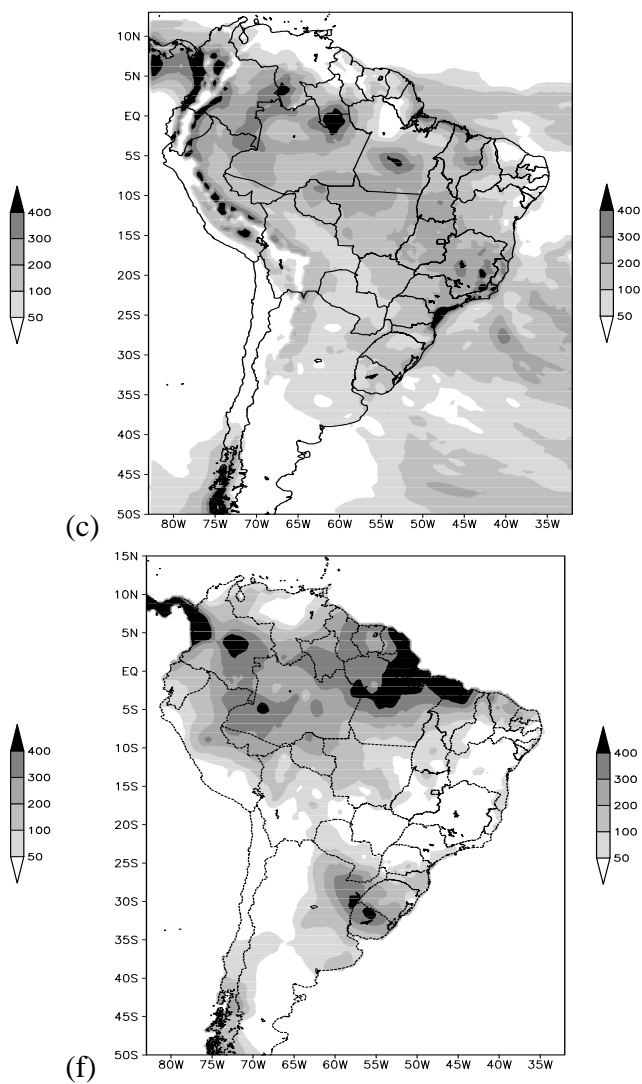

(h)

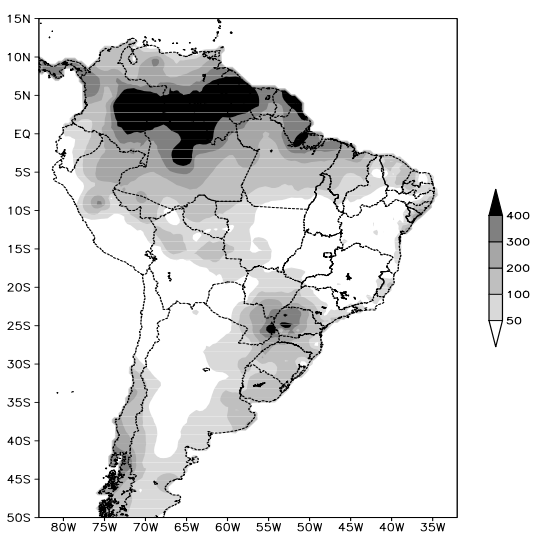

Fig. 8. FMAM monthly total precipitation (mm): February (a) Eta forecast and (b) observed; March (c) Eta forecast and (d) observed; April (e) Eta forecast and (f) observed; and May (g) Eta forecast and (h) observed.

Figure $8 \mathrm{a}-\mathrm{h}$ show the precipitation fields for the months of FMAM. In FMAM the rains started to reduce in the central part of the continent from March in the observations. The forecasts showed some delay of this rain reduction as some major areas of predicted precipitation remained in that region. The Intertropical Convergence Zone is the major precipitation producer in the north of the continent and Northeast Brazil during this season. The ITCZ was positioned farther to the north of its climatological position during this year as was shown in Climanálise (2002). The rains over Northeast Brazil were reasonably forecast by the model, however, in every month, the forecasts underestimated the rains along the coast of the northern states of Brazil. The transition to the dry period was delayed in the forecasts, as it still showed a large raining band over the central and southeastern part of Brazil in March. These raining areas have been largely reduced from March to April in the observations. In May, the fourth month of integration, the no-rain areas were correctly predicted by the model.

Figure 9a-h show that in MJJA months the major raining areas were located to the north of Amazon and in southern Brazil. These precipitation regions were well captured by the model. Along the eastern part of Northeast Brazil, the forecasts clearly overestimated the coastal rains in the months of May and June. These rains are produced by the easterly traveling perturbations originated from the Southern Atlantic 
(a)

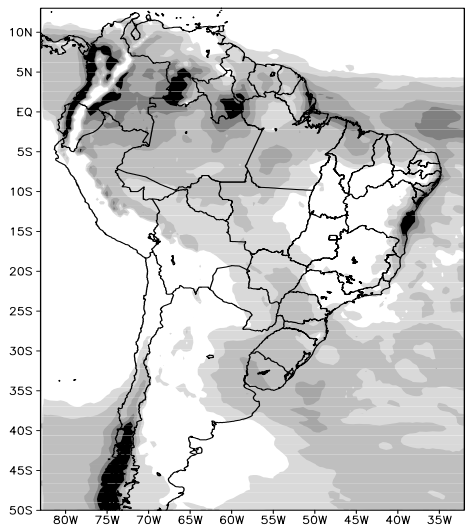

(d)

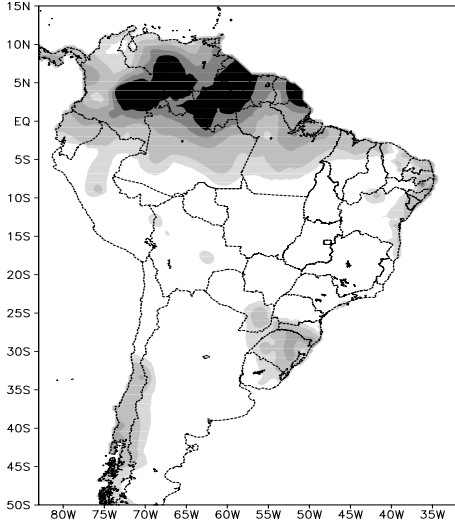

(g)

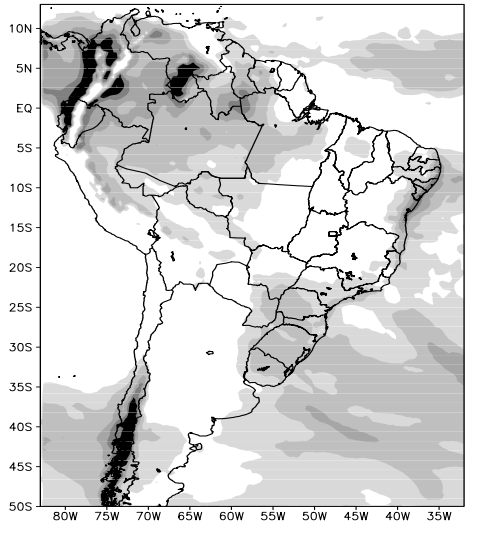

(b)
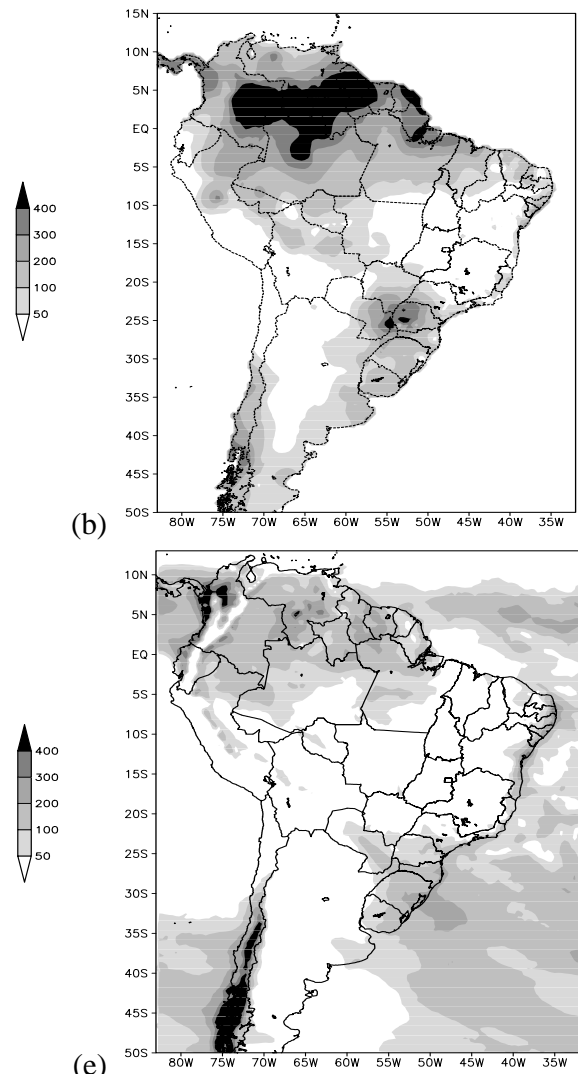

(e)

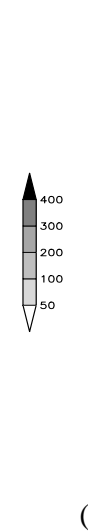

${ }^{15 N}$
$10 \mathrm{~N}$
$5 \mathrm{~N}$
60
55
105
155
205
255
305
355
405
455
505

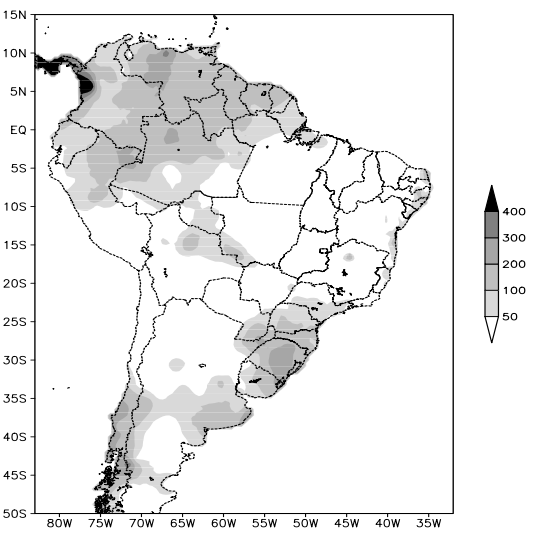

(c)
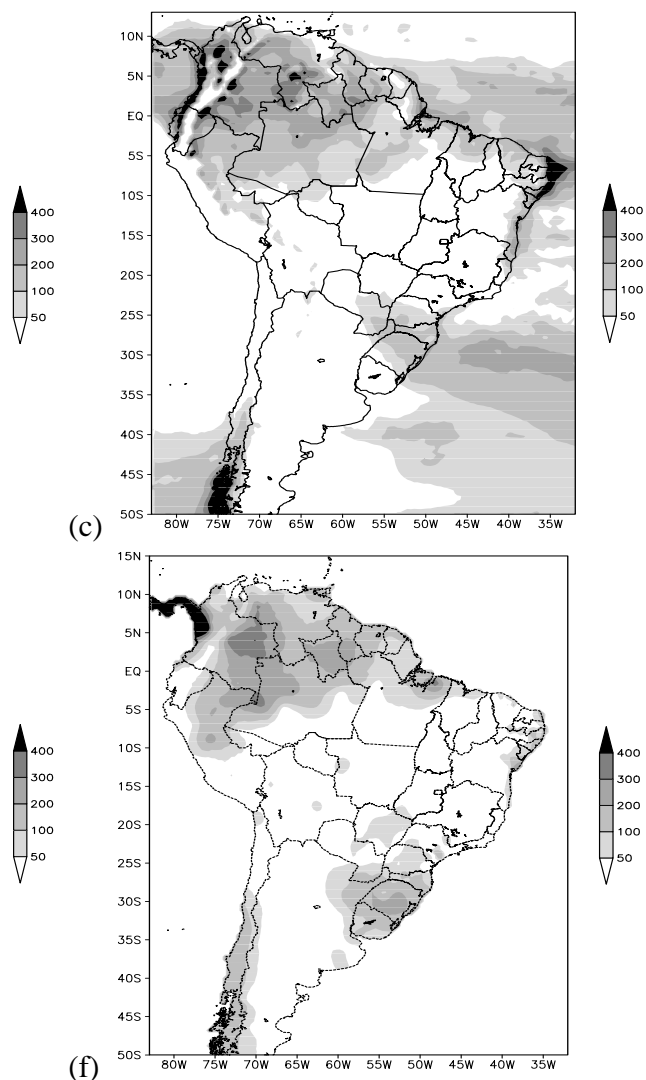

Fig. 9. MJJA monthly total precipitation (mm): May (a) Eta forecast and (b) observed; June (c) Eta forecast and (d) observed; July (e) Eta forecast and (f) observed; and August (g) Eta forecast and (h) observed.

anticyclonic circulations. The rains are overestimated as the winds from the lateral boundary conditions are strong, perpendicular to the coast and carry moisture inland. In weather forecasts, the Eta Model tends to underestimate the rains of this region, which are mostly produced by warm clouds. This indicates that the model has different bias in different integration ranges. Misra (2003) compared model errors in different climate scales and found distinct bias in distinct forecast ranges.

In ASON months (Figs. 10a-h) major raining areas remained in the northern part of the Amazon and southern Brazil. The rains in the central region started to resume in October which are characterized by generalized rains in the central part of Brazil. Generally, rains resume in October. The model seems to have captured this return of the rainy season, but overestimated the area of these rains.

NDJF months (Figs. 11a-h) are the summer months. They are characterized by generalized deep convective precipitation over the central part of the continent. The forecasts of the rainy season showed some underestimate in December, when the major band was already clearly defined in the observations. The forecasts of the monthly totals of precipitation positioned correctly the SACZ. The predicted magnitude of precipitation in all months was comparable to observations. However, some localized precipitation maxima were missed by the model, for example the observed precipitation 
(a)

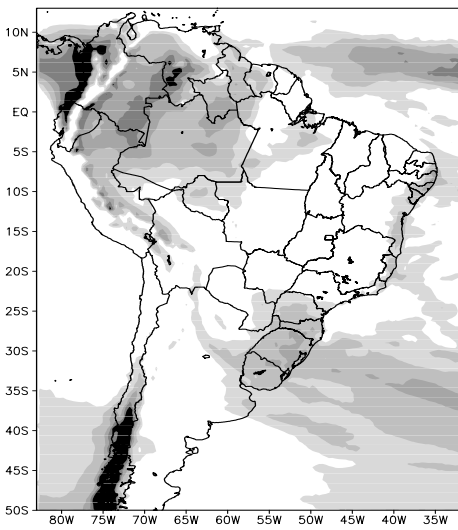

(d)

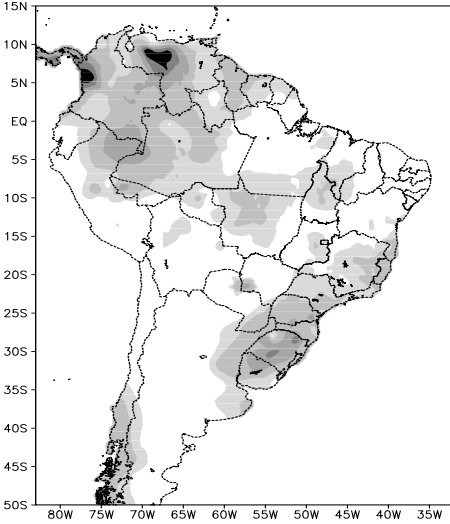

(g)

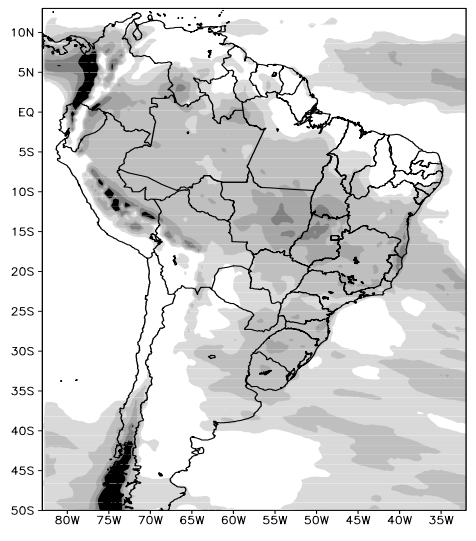

(b)
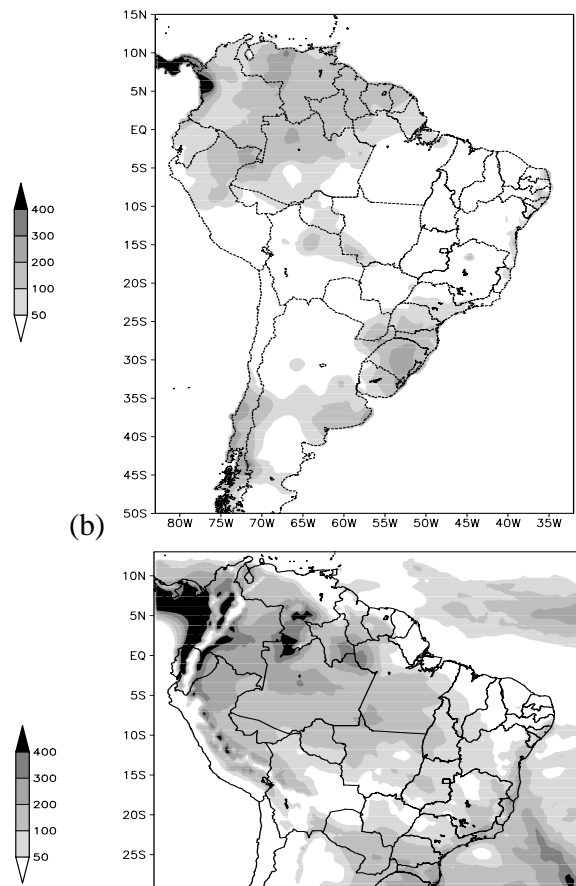

(e)
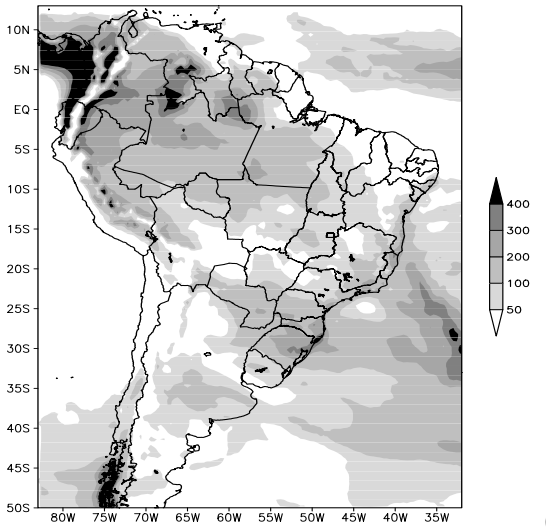

(f)

(c)
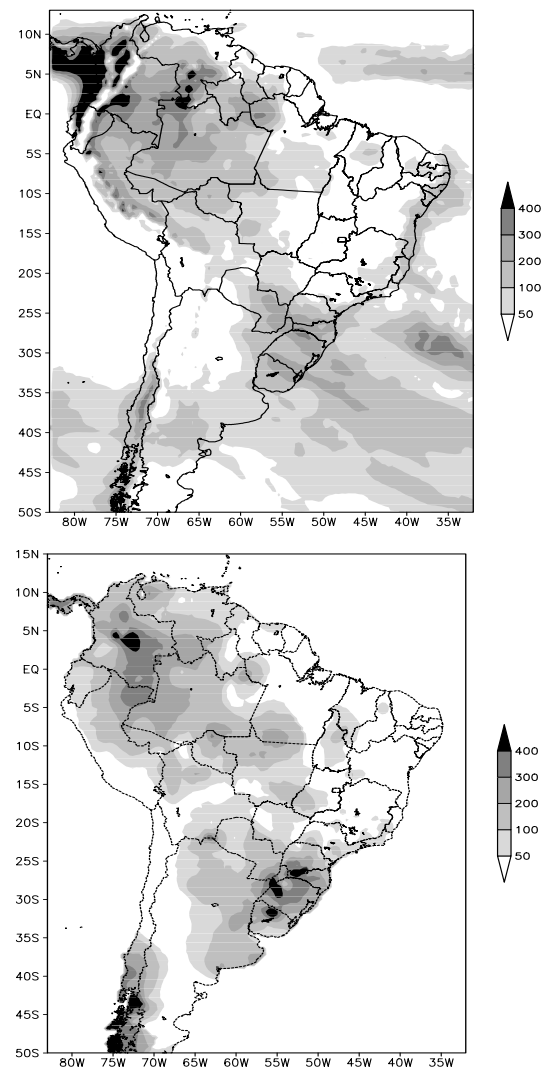

(h)

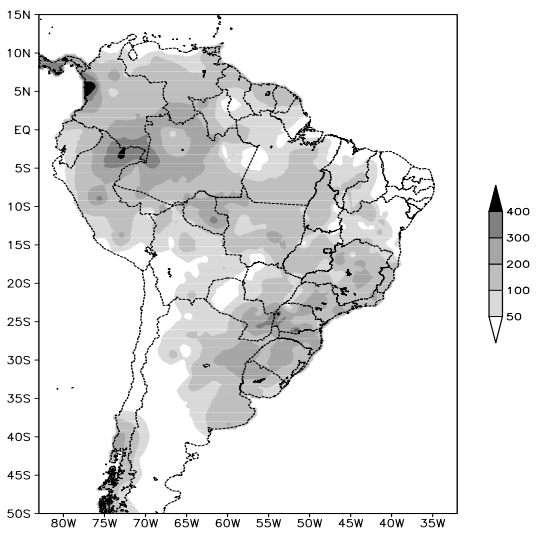

Fig. 10. ASON monthly total precipitation (mm): August (a) Eta forecast and (b) observed; September (c) Eta forecast and (d) observed; October (e) Eta forecast and (f) observed; and November (g) Eta forecast and (h) observed.

maxima in southeastern Brazil in December and January.

\subsection{Equitable threat scores}

Monthly total precipitation forecasts are evaluated objectively against observations by the equitable threat score (ETS) which is defined as:

$\mathrm{ETS}=\frac{H-C H}{F+O-H-C H}$,

where: $F$ is the number of forecast points above a threshold, $O$ is the number of observation points above a threshold, $H$ is the number of hits and $C H$ is the number of points of ran- dom hits, defined as $(F \times O) / N$ and $N$ is the total number of points evaluated.

A companion score is the bias score defined as $F / O$. A perfect forecast would, therefore, result in $\mathrm{ETS}=1$ and bias $=1$.

The scores were evaluated for different precipitation rate thresholds. Observations were analyzed onto the model 40$\mathrm{km}$ output grid. The evaluation was performed only on the grid-boxes which contained at least one observation station. Different weather systems prevail over different regions of the continent. The scores were produced for 4 regions (Fig. 12): the Amazon region (AM), within $15^{\circ} \mathrm{S}$ to $12^{\circ} \mathrm{N}$ and $70^{\circ} \mathrm{W}$ to $45^{\circ} \mathrm{W}$, the Northeast region (NE), within 
(a)

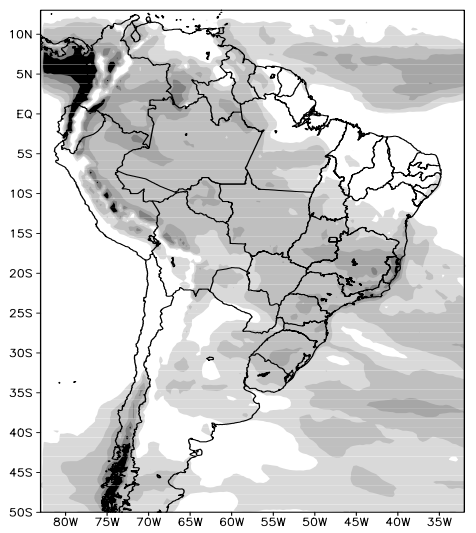

(d)

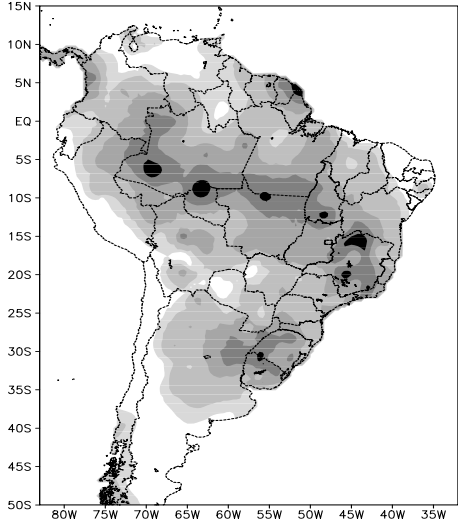

(g)

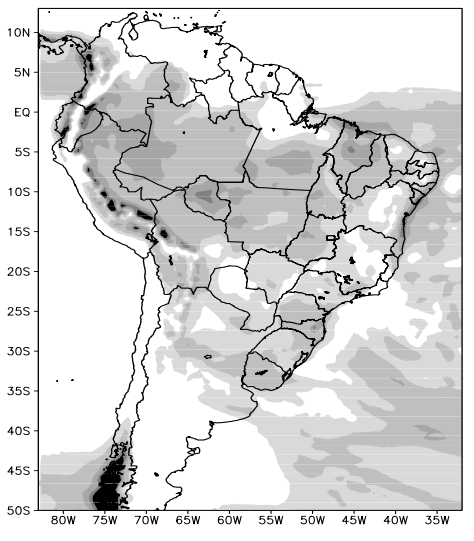

(b)

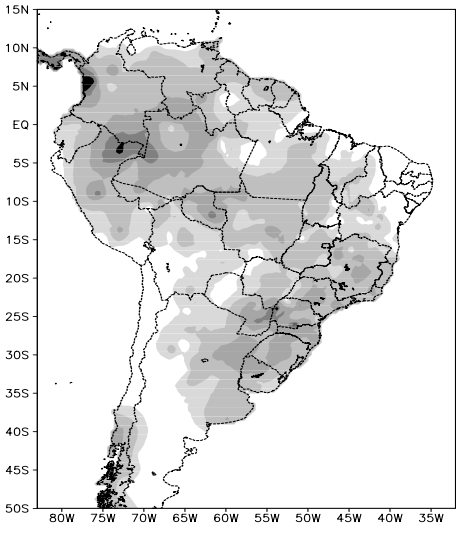

(e)
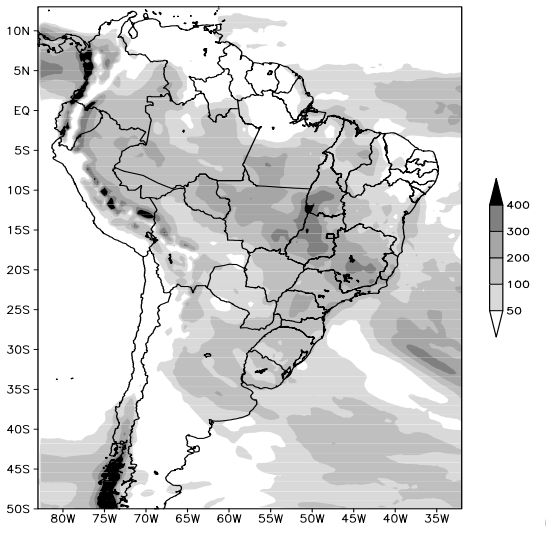

(f)

(c)
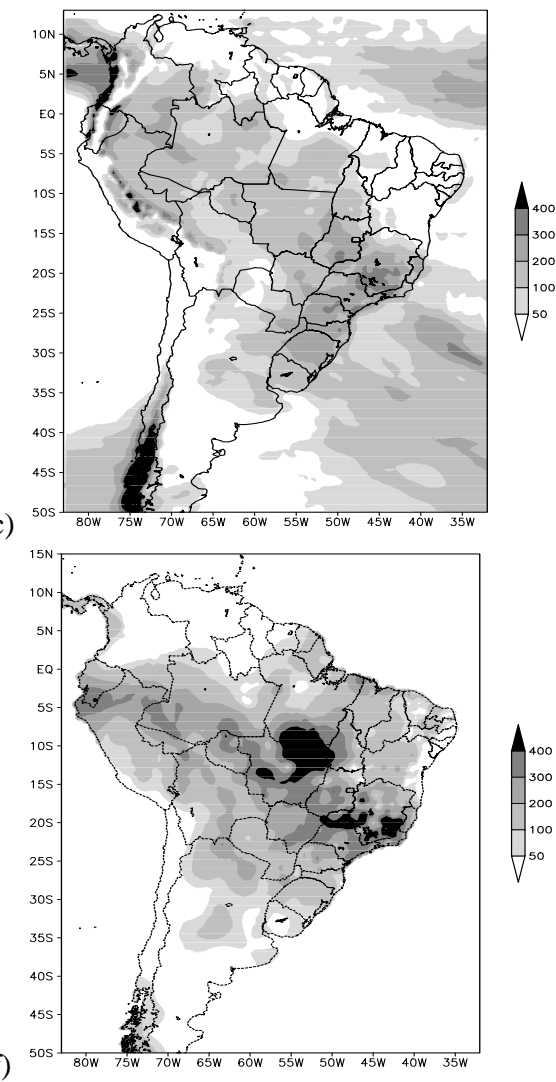

(h)

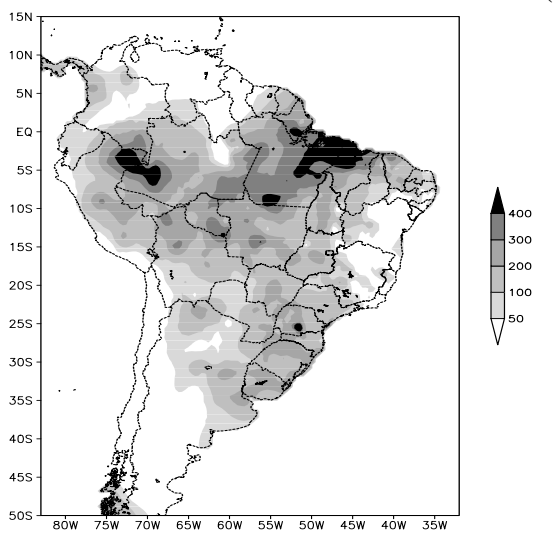

Fig. 11. NDJF monthly total precipitation (mm): November (a) Eta forecast and (b) observed; December (c) Eta forecast and (d) observed; January (e) Eta forecast and (f) observed; and February (g) Eta forecast and (h) observed.

$15^{\circ} \mathrm{S}$ to $12^{\circ} \mathrm{N}$ and $45^{\circ} \mathrm{W}$ to $32^{\circ} \mathrm{W}$, the Center-South region (CS), within $15^{\circ} \mathrm{S}$ to $50^{\circ} \mathrm{S}$ and from $70^{\circ} \mathrm{W}$ to $32^{\circ} \mathrm{W}$, and the whole South America region (SA). In the Amazon region, precipitation is primarily produced by isolated showers from deep convection, but at times some organization can be noticed due to the approach and activity of the ITCZ or a frontal passage reaching lower latitudes. In the Northeast of Brazil, although this is a small region, precipitation distribution is highly spatially heterogeneous. In the northern part of Northeast Brazil, heavy precipitation is produced by combination of ITCZ and sea breeze circulation, whereas, in the eastern coast of Northeast Brazil, precipitation is produced by frequent easterly travelling disturbances from the Atlantic anticyclone during winter months. Those rains are generally produced by heavily water loaded low-top clouds. The Center-South region is mostly affected by the frontal systems travelling equatorward. Mesoscale complexes are frequent during warm and autumn season. Figure 12 shows the distribution of grid-boxes which contained at least one observation station. The surface station used in this work is the most complete available dataset for the Brazilian area, which represents most of South America. The Amazon region has large observation void areas. The scores over this region are mostly based on stations located along the major rivers.

Figures 13a-d show the ETS and bias for the 4 regions in FMAM, MJJA, ASON and NDJF for the Eta Model. The 
precipitation thresholds refer to monthly total values.

In FMAM, the ETS (Fig. 13) were relatively high at most of thresholds. The bias score was slightly above, but close to, 1 , which indicates that rains are generally well forecast at most thresholds, except at heavier precipitation rates, which were underestimated by the forecasts. In FMAM months, the Intertropical Convergence Zone is located in its southernmost latitude and rains are more frequent over the Amazon Basin. The scores for Center-South and Amazon regions were similar, showing higher performance at weaker rains and lower at heavier rains. The bias scores are close to 1 . Druyan et al. (2002) reproduced forecasts for this period of the year, and also found higher correlation between forecast and observed precipitation over the Amazon region. This is the rainy season of Northeast Brazil, however, the scores are lowest for this region.

In MJJA (Fig. 13b), the number of precipitation events have reduced considerably relative to the previous 4 seasons. The scores of all regions have also decreased relative to FMAM. The Amazon region suffered the largest reduction. The bias score exhibited larger spread among the regions and indicated the overestimate of MJJA rains. The Northeast region showed large bias, which was partially caused by the large overestimate along its eastern coast, as seen in Fig. 2.

In ASON months (Fig. 13c), the onset of the South America Monsoonal System is the major event. Generally, the rains start to resume in the central part of the continent between September and October. The ETS in the Center-South regions started to improve relative to the previous season. Higher precipitation rates showed lower scores in the Amazon region. The Northeast region showed a large decrease of ETS accompanied by a large increase in bias. In ASON months, the four regions exhibited the largest precipitation overestimate compared to other periods and the overestimate occurred at practically all precipitation thresholds. The model scored lowest in this season.

In NDJF (Fig. 13d), the Center-South region scored higher ETS at smaller amounts of precipitation. At moderate rains, the Amazon region scored higher than the other region. These two regions showed similar curves, on the other hand, the ETS in the Northeast Brazil departed from the other 3 curves. Rains are not frequent in Northeast Brazil this time of the year. Ensemble precipitation distribution obtained by Druyan et al. (2002) achieved higher correlation with CMAP (Xie and Arkin, 1997) for the Amazon region precipitation distribution. The bias score of the 4 regions generally showed values near or above 1 . The overestimation has reduced considerably compared to previous season.

A feature common to Eta Model forecasts of all seasons was the high ETS at the lowest precipitation thresholds in the 4 regions, but the skill of those regions decreased with precipitation intensity. This is intuitive that the quantitative value of extreme precipitation events are difficult to be captured by models. This difficulty results in underestimate of higher precipitation rate thresholds and bias smaller than 1 .

The verification of the forecasts from the driver model may provide some hints on the error sources of the regional model

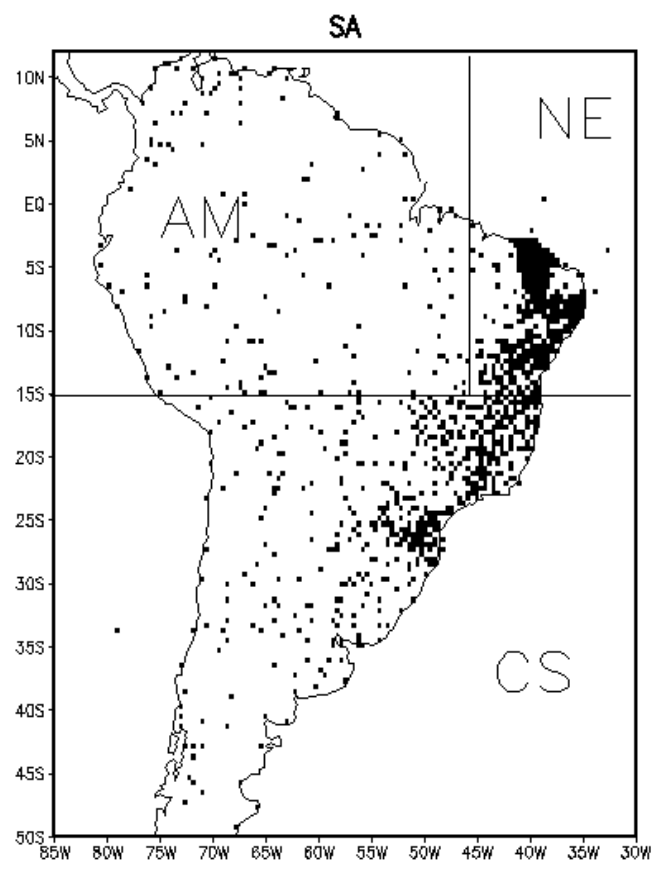

Fig. 12. Domains where the Equitable Threat and Bias Scores were calculated: SA, for South America, AM, for Amazon region, NE, for Northeast region, and CS, for Center-South region. The squares are model output grid-boxes where surface precipitation observations were available.

forecasts. In FMAM, the CPTEC GCM precipitation forecasts (Fig. 14a) showed smaller ETS compared to the Eta Model scores at all thresholds. On the other hand, in Northeast Brazil the CPTEC GCM ETS was slightly larger than the Eta score, particularly at lower thresholds, however, this larger ETS was also accompanied by large overestimate.

In MJJA, the CPTEC GCM ETS showed a significant decrease of skill in most regions (Fig. 14b). The GCM ETS values were lower than the Eta ETS for all the regions. The CPTEC GCM failed to forecast some of the frontal passage events in the southern part of the domain which resulted in large underestimate of precipitation in the Center-South region, as it was indicated by the bias score.

In ASON, the CPTEC GCM increased the forecast skill over the Center-South region (Fig. 14c). The skill over the Amazon region was lower than the Center-South region. In Northeast Brazil, the GCM ETS became slightly higher than the Eta score. The bias scores of both models were comparable. For this season of monsoonal onset, both models seemed to show similar precipitation forecast performance.

In NDJF, the major rainy season of the continent, the CPTEC GCM ETS (Fig. 14d) showed lower skill in the Amazon and Center-South regions compared to Eta Model skill. On the other hand, in Northeast Brazil, the GCM skill was slightly higher than the Eta, although a large bias was shown in the GCM precipitation forecasts. In the Center-South region, the CPTEC GCM ETS showed a large drop of skill at moderate precipitation rates, but in this region small bias scores occurred at those precipitation rates. 
(a)

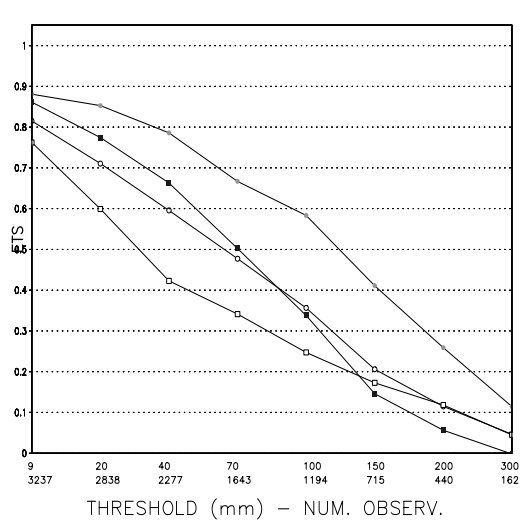

(d)

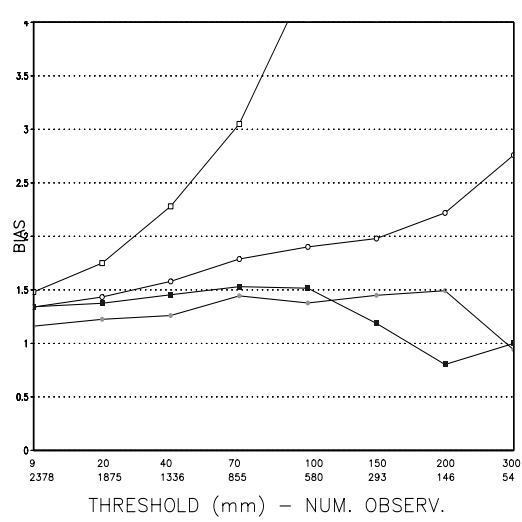

$(\mathrm{g})$

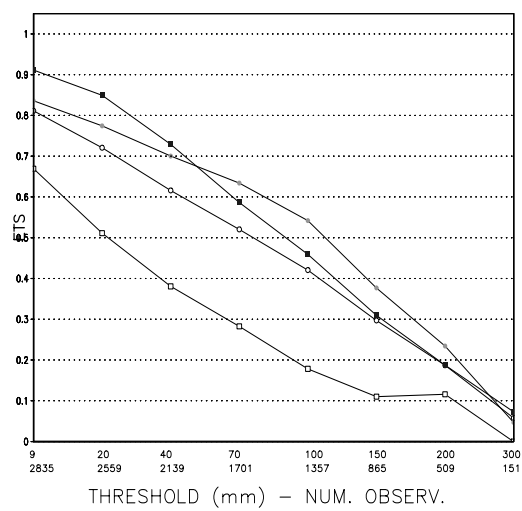

(b)

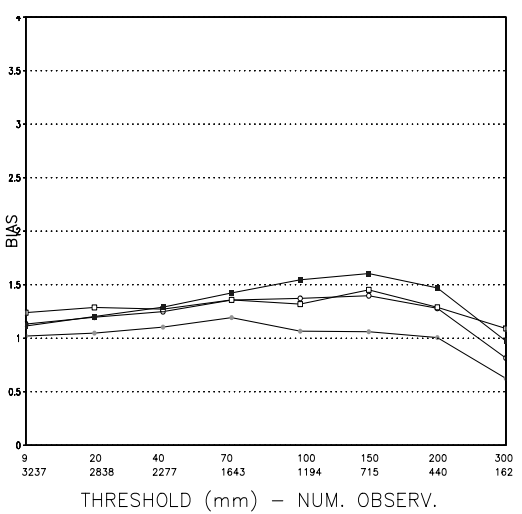

(e)

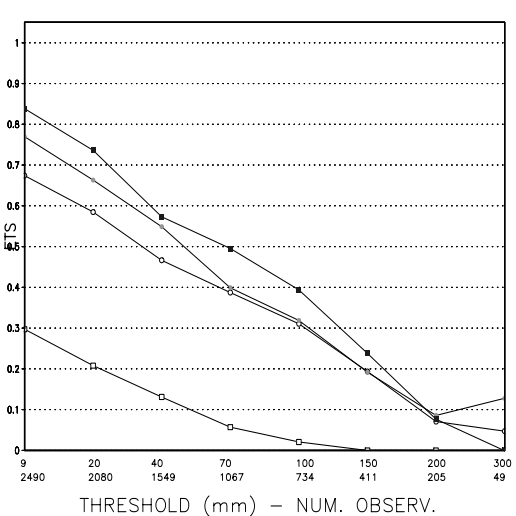

(h)

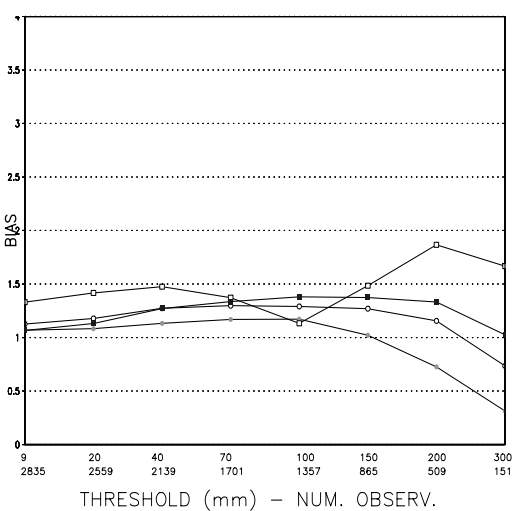

(c)

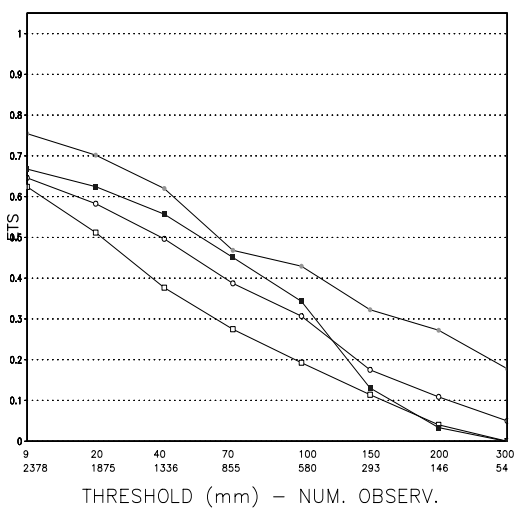

(f)

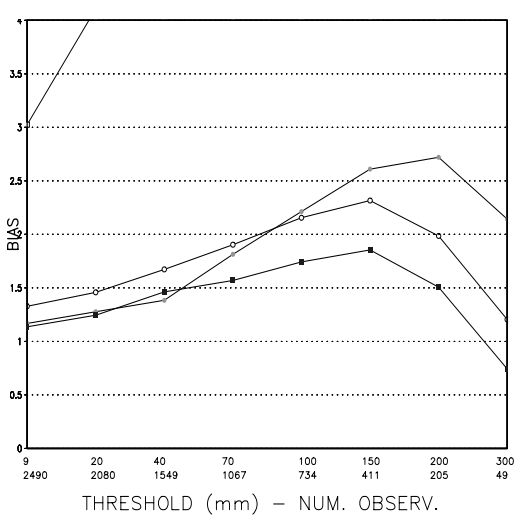

Fig. 13. Eta Model monthly total precipitation equitable threat score (ETS) and bias Score for: (a) FMAM, (b) MJJA, (c) ASON and (d)

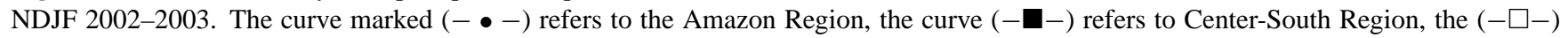
refers to Northeast Brazil Region and the (- - -) refers to the whole South America domain. The second label refers to the total number of observations that occurred above each threshold over South America

In general, both models produced better forecast skill over the Amazon region, whereas over the Northeast of Brazil the scores were lower. Misra (2003) evaluated the predictability of this region based on the COLA GCM. He showed, however, that the precipitation errors in Northeast Brazil are smaller than the errors over the Amazon, indicating a higher predictability over Northeast Brazil by the COLA model. The predictability of the Northeast region climate should be higher than that of the other regions due to the strong sea surface temperature control on the local circulations. The
CPTEC GCM which provided the lateral boundary conditions showed higher predictability over this region in the work carried out by Cavalcanti et al. (2002), based on precipitation anomaly forecasts. However, considering the absolute precipitation value, both the GCM and the Eta Model showed the highest skill in the Amazon region and the lowest skill in Northeast Brazil. The bias scores showed that the precipitation forecasts were largely overestimated by the CPTEC GCM at all seasons. 
(a)

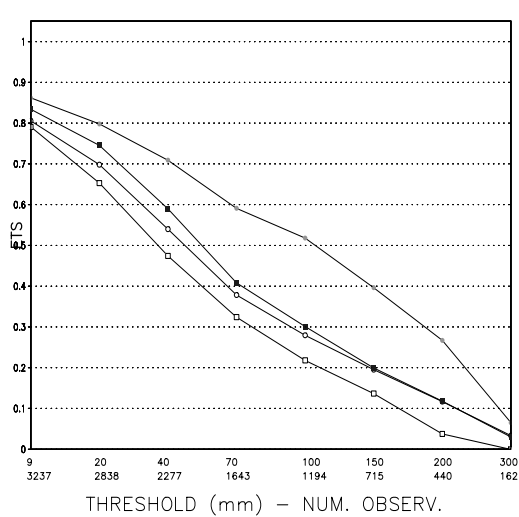

(d)

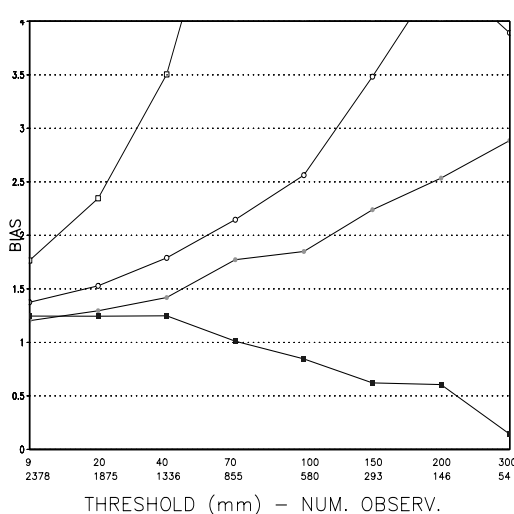

$(\mathrm{g})$

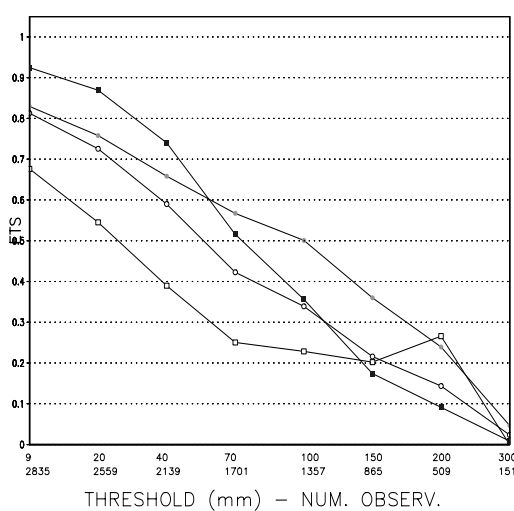

(b)

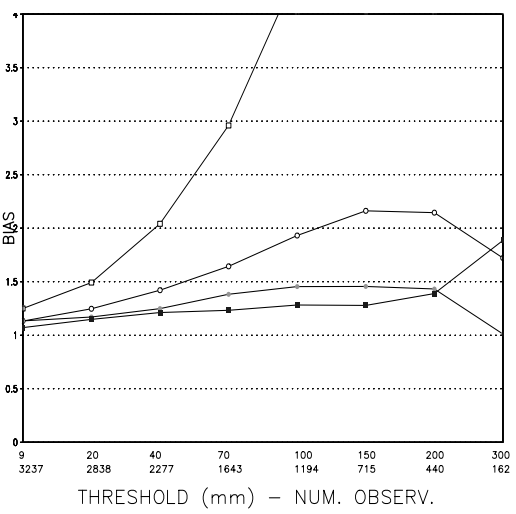

(e)

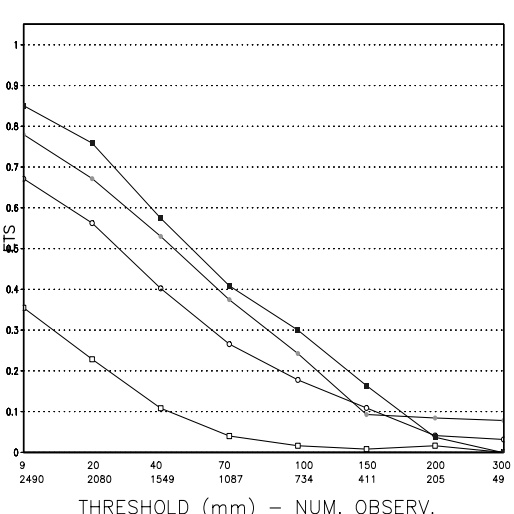

(h)

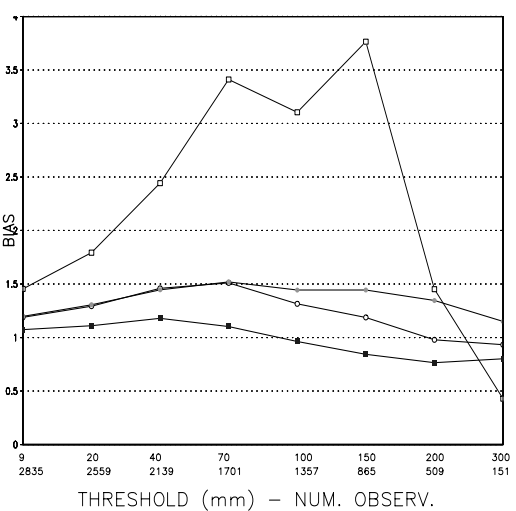

(c)

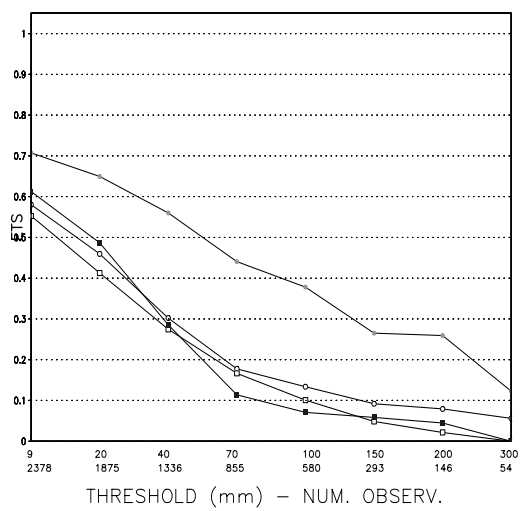

(f)

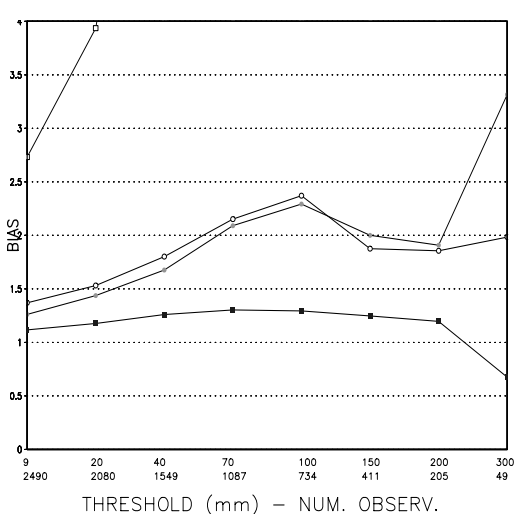

Fig. 14. CPTEC GCM monthly total precipitation equitable threat score (ETS) and bias score for FMAM 2002. The curve marked (- --$)$ refers to the Amazon Region, the curve (- - -) refers to Center-South Region, the $(-\square-)$ refers to Northeast Brazil Region and the ( $-\circ-)$ refers to the whole South America domain. The second label refers to the total number of observations that occurred above each threshold over South America

\subsection{Monthly forecast lead time}

Global model seasonal forecasts show skill at low resolution. In downscaling, it is expected that some higher spatial and temporal resolutions can be added by the regional models. An indication of the range of predictability of the regional model can be assessed by evaluating the skill as a function of the monthly lead time. Thus the ETS is, in this section, extended to evaluate precipitation forecast at different forecast lead times: month 1 , month 2 , month 3 and month 4 . Twelve seasonal forecasts were taken into account for the calculation of the score.

Figure 15a shows that equitable threat scores for the month 1 of integration were for most categories higher than the scores for month 2 . The month 3 and month 4 also scores higher than month 2 , especially at higher precipitation rates. The scores of the four lead times were not too different from one another.

The bias score (Fig. 15b) of one-month lead time showed values generally close to 1 , which indicate some overestimate 
(a)

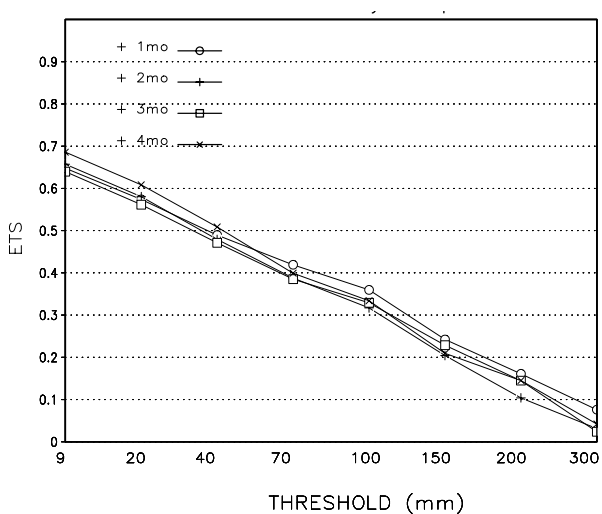

(b)

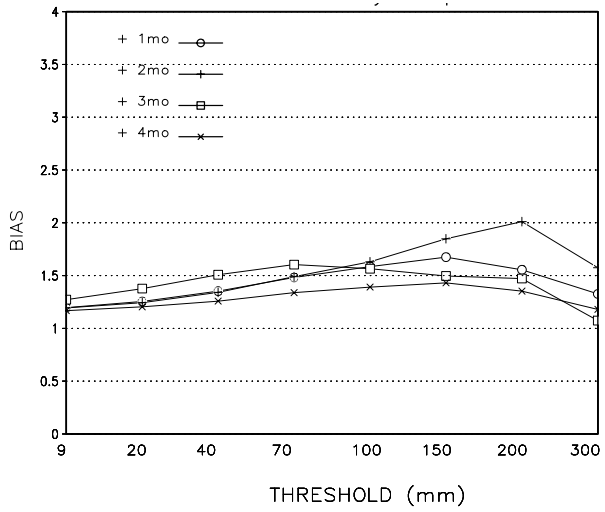

Fig. 15. Equitable Threat Score (a) and Bias Score (b) for different forecast lead months.

of rains. The month 2 forecasts show the largest bias at higher precipitation rates. The month 4 forecasts show smallest bias at all precipitation thresholds.

The combination of the two scores indicate that precipitation is best forecast in the month 1 , however, there is no significant difference among the four months lead times. The overestimation occurs at all thresholds. In the precipitation pattern comparisons, the observed precipitation are analyzed onto a regular grid and localized precipitation maxima centers are spread, which can suggest an overestimation of precipitation in a pattern comparison. The localized heavy precipitation centers are under-predicted by the model, but these events are less frequent.

It is not clear what might be the reason for the decrease of model forecast performance at month 2 then followed by an increase in months 3 and 4. One could expect that soil moisture spin-up time would result in the month 1 forecast performance lower than the month 2 , however, this did not happen in the runs of this year. It seems that the forecast errors are not dominated by surface conditions in the Eta Model. In the extended range simulations carried out by Chou et al. (2003), the model predictability was more strongly controlled by lateral boundary conditions rather than the lower boundary conditions provided by the sea surface temperature.

\subsection{Comparison against climatology}

In the lack of a numerical tool, a seasonal forecast would be based on the climatology information. To show that the Eta Model forecasts could be considered improvement over the climatology, a comparison between the two precipitation fields and the observations would be necessary. The forecast error of season total precipitation, defined as forecast minus observation, was calculated. The climatology error, defined as climatology minus observation, was calculated and compared with the forecast error. The monthly precipitation climatology was produced by the GPCC (Global Precipitation Climatology Centre) at $2.5^{\circ} \times 2.5^{\circ}$ latitude-longitude resolution. This dataset is based on observed in situ gauges of 30 years, from 1961 to 1990 (Rudolf et al., 2003).

Figure 16 shows the mean error calculated over the four seasons and over the four regions defined in Fig. 12. The largest forecast errors were found over the Amazon region, whereas the smallest errors occurred in the Center-South region. During the rainy seasons, FMAM and NDJF, the Eta Model clearly showed advantage over the climatology as the forecast errors were much smaller. On the other hand, during the ASON season, the forecast errors are larger than climatology errors in all regions. In ASON, although the precipitation pattern was well forecast, the amounts show large positive errors. In MJJA, the largest overestimate of the Eta Model was found in Northeast Brazil which seems to be a signal transferred from the driver model. The mean errors showed that the climatology systematically overestimated the precipitation. This positive climatology error, actually indicates an anomalous dry year. The advantage of the model over the climatology was shown as the forecast exhibited generally smaller mean error. The model indicated some ability to capture inter-annual variability, which the climatology information would not provide.

\subsection{High frequency variability}

It is not expected that seasonal integration forecasts can have skill in capturing the correct date of the event occurrence of a weather event, however, it is expected that some of the regime of the frontal passage, or some internal high frequency can be indicated by these forecasts.

Figure 17 (left column) shows the one-month sequences of predicted precipitation and meridional wind taken along the eastern coast of Brazil for the NDJF run, the rainy season. The positive values of the meridional wind indicate the frontal progression in the cold air side. The shaded areas indicate the precipitation activity related to the frontal system. The diagnosed paths of the fronts are marked as the front passes over major cities along the eastern coast of Brazil (Fig. 17, right column). The diagnostics of the frontal passages are based on satellite image and surface observations. The number of observed frontal passages was about 7 per month.

In the first month, the model predicted about 6 frontal progressions, among which two showed a farther northern 
Mean Error N

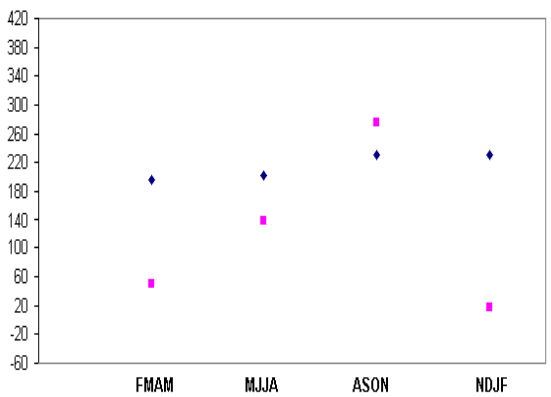

(a)

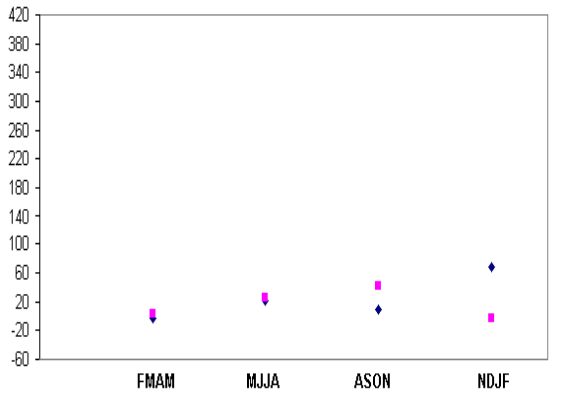

(c)

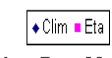

Mean Error CS

+Clim $-E t a$ (b)
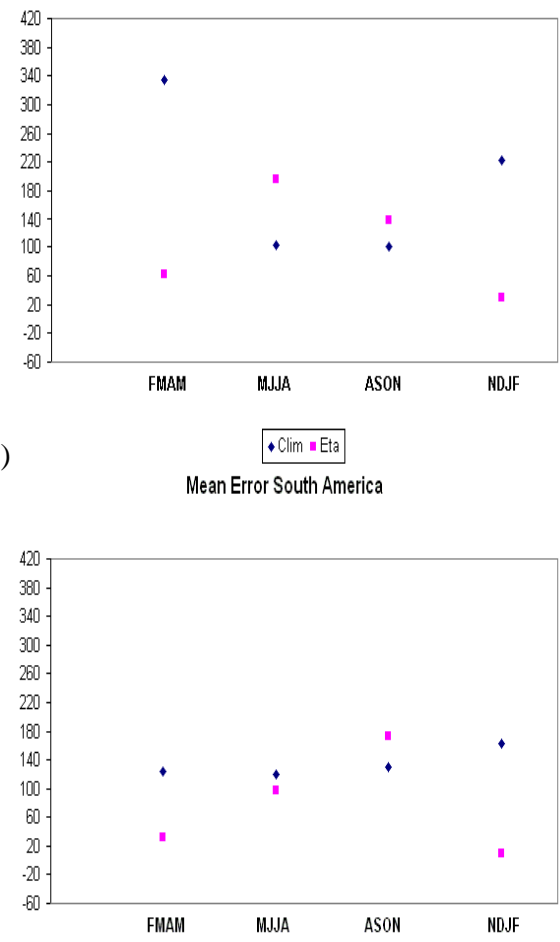

(d)
Mean Error NE

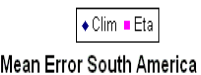

+ Clim - Eta

Fig. 16. Mean precipitation forecast errors (squares) and climatology errors (diamonds) (mm) in the regions: (a) Amazon, (b) Northeast, (c) Center-South and (d) whole South America.

displacement. This regime roughly agreed with the observation which also showed about 6 to 7 events of frontal northward displacement.

At the latitude around $20^{\circ} \mathrm{S}$, fronts frequently tend to change direction and move eastward and southeastward. In the second month (Fig. 17b), the northerly winds, indicated in the forecasts by the positive values, reached about $15^{\circ} \mathrm{S}$, which suggested some blocking situation of the frontal progression to the north. The observations also indicated some blocking scenario as the front position remained around $23^{\circ} \mathrm{S}$ for several days in December 2002.

In the third month (Fig. 17c), January, the forecast indicated less frequent fronts and fronts with northward displacement in the first half of the month. The observation did not show clearly this behavior, although two initial events were positioned more to the north. In the fourth month (Fig. 17d), the predicted precipitation activity located at lower latitudes refers to the tropical easterly weak disturbances. These tropical events are not marked in the observed frontal track diagrams. In this month, February, the model indicated less frequent frontal passages blocked at about $24^{\circ} \mathrm{S}$. The observations seem to verify this feature with small displacements of the fronts.

Although the interpretation of the frontal regime is very subjective, the model forecasts seemed to give some indication of the frontal behavior in the rainy season.

\subsection{Weekly evaluation}

In the analysis above, one can notice that as more temporal resolution is sought, the model precipitation predictability is reduced, although still showing some skill. In this section, 7-day mean values of precipitation from seasonal forecasts are evaluated.

An example of application of seasonal forecasts for hydrology is the work carried out by Kyriakidis et al. (2001). They used the precipitation forecast from RCSM (Kim et al., 2000) to generate an ensemble forecast as input to a semidistributed hydrological model. The daily forecast precipitation showed a mismatch with observations. The model generally underestimated the amount and the frequency of the rains over the basin. The forecast stream flow derived from the forecast precipitation was consequently underestimated. A mean value of forecast precipitation over 7 days may improve the skill and the usefulness of the precipitation forecast, which is applied to the São Francisco Basin.

The São Francisco Basin is the major basin for the energy and water supplies for Northeast Brazil. Figure 18 shows roughly the basin domain. The total precipitation was averaged in the basin area and summed over 7-day periods.

Figures 19a-d show the temporal sequence of the 7-day basin averaged precipitation for the 4 seasons. In FMAM, the rains started to reduce, but the forecasts indicated the 

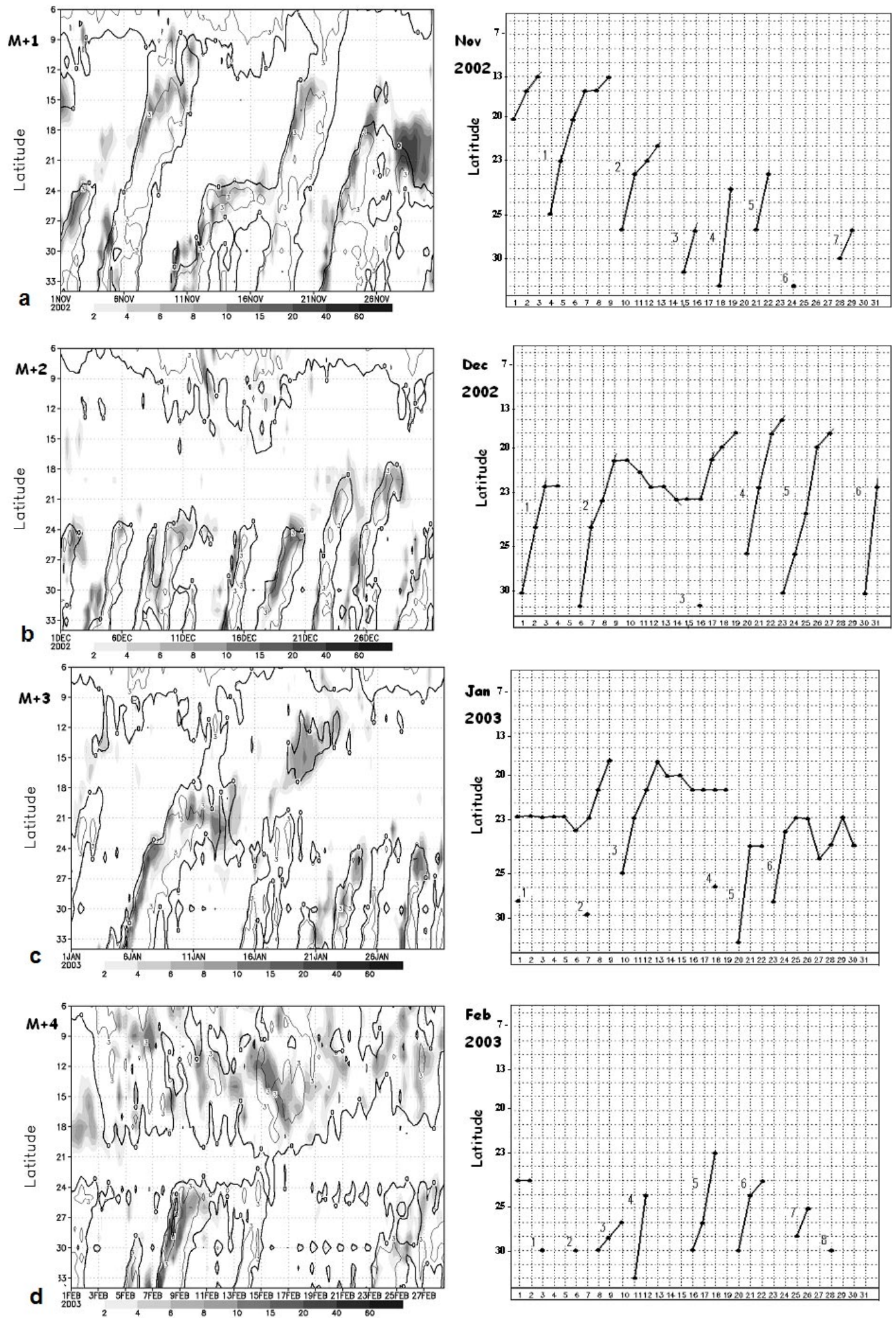

Fig. 17. NDJF frontal passages along the eastern coast of Brazil indicated by precipitation (shaded) and meridional wind, where solid contours refer to southerly winds. (a) November (b) December, (c) January, and (d) February. The right column refers to Observation and the left column refers to Forecast.

some increase between the second half of March and first half of April, which was followed reasonably by the observations. The forecasts tended to start with larger amounts of rains than observation in these two seasons, when rains are more frequent. In the following season, MJJA, a strong reduction of precipitation over São Francisco Basin was observed. The forecasts indicated correctly this strong reduction, but it underestimated the total rains, which suggested a 
Table 1. São Francisco Basin: 7-day mean precipitation: Eta and observations; correlation between forecast and observed 7-day mean precipitation; root mean square error of the forecast; standard deviation of forecasts and observations.

\begin{tabular}{ccccccc}
\hline season & $\begin{array}{c}\text { Eta } \\
\text { mean }\end{array}$ & $\begin{array}{c}\text { Obs } \\
\text { mean }\end{array}$ & Corr & RMSE & $\sigma_{\text {eta }}$ & $\sigma_{\text {obs }}$ \\
\hline NDJF & 27 & 35 & 0.33 & 27 & 20 & 24 \\
FMAM & 22 & 14 & 0.17 & 22 & 16 & 16 \\
MJJA & 1 & 4 & 0.32 & 4 & 1 & 3 \\
ASON & 17 & 9 & 0.26 & 21 & 18 & 15 \\
\hline
\end{tabular}

negative precipitation bias for the basin during this season. The rains of ASON are critical and most expected because of the demand on hydro-energy and the extensive areas of forest burnings during the dry period. The forecasts for ASON indicated two major precipitation events, but gave false alarm to a precipitation event in mid-October. In NDJF, the forecasts indicated an increase of the rains from the second half of December 2002 until the first half of January 2003, and smaller amounts in November 2002 and February 2003. This matched roughly with observations. The model tended to advance the return of the rains compared to observations.

Table 1 lists the basin average value of the precipitation over each month and season. The forecasts did not show a clear systematic bias, at any particular season. The standard deviation showed that the temporal variability of the predicted precipitation within the basin is close to the observed variability. The linear correlation between the observed and the forecast 7-day mean time series is always positive which indicates that the model time tendency is generally correct, although these correlation values are small at all seasons. The rainy season, NDJF, shows higher precipitation forecast correlation with observations.

\section{Conclusions}

Seasonal precipitation forecasts produced by the $40-\mathrm{km}$ resolution Eta Model configured over South America were evaluated for one year period. The precipitation predictability evaluation focused on the different forecast ranges: seasonal, monthly and weekly, and over 4 major regions: the whole South America, the Amazon region, the Northeast Brazil and the Center-South region. Some comparisons with the driver model were also carried out.

In general, large scale precipitation features over South America such as the Intertropical Convergence Zone, the South Atlantic Convergence Zone and the Amazon convection were well described in the seasonal forecasts. The magnitude of the predicted precipitation was in good agreement with observations.

In monthly evaluation of precipitation, the model showed it can describe the intra-seasonal variability, which was better revealed in the transition seasons. Although some decrease

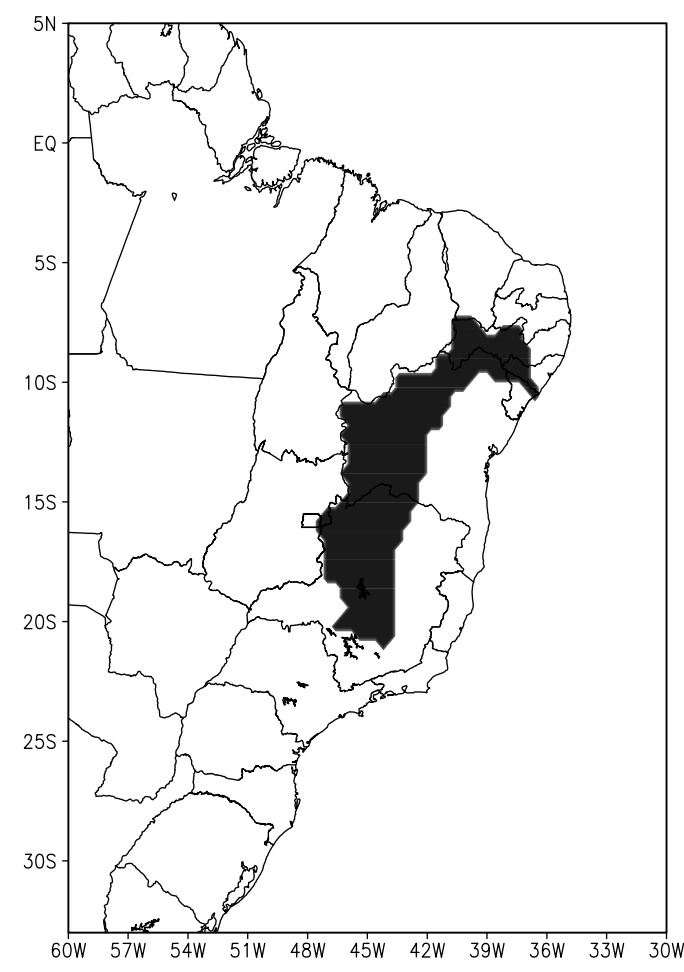

Fig. 18. São Francisco Basin is shaded.

of forecast performance relative to seasonal values can be noticed, the monthly forecast total values gave reasonable indication of the observed precipitation.

The forecasts showed some systematic overestimate of precipitation along two preferred coastal regions: Chilean Andes and the eastern coast of Northeast Brazil. These errors are partly due to stronger winds near the boundaries provided by the driver model. The driver model winds in those regions were more perpendicular to the coast and stronger than the observed. The CPTEC GCM produced larger precipitation overestimate than the Eta Model. This excess of rain seemed to be partly transferred to the regional model.

Objective evaluation of monthly precipitation forecasts based on equitable threat scores showed higher scores at weaker thresholds and decreasing scores toward higher precipitation totals. The lowest threshold can be regarded as the rain-no rain threshold. This indicates that the model forecasted well the rain areas. The bias score indicated that the model tended to overestimate precipitation at most thresholds, except at heavier rates. The Eta bias score indicated a small overestimate of the forecasts at low and moderate thresholds, and some underestimate at the highest thresholds. The scores showed that at the fourth month of integration, the model performance was still comparable to that at the shorter monthly ranges, the first month of integration showed the highest scores. Compared to CPTEC GCM ETS, the Eta ETS were generally larger and the bias were generally smaller, which indicated an improvement of the Eta in downscaling the driver model features. 
(a)

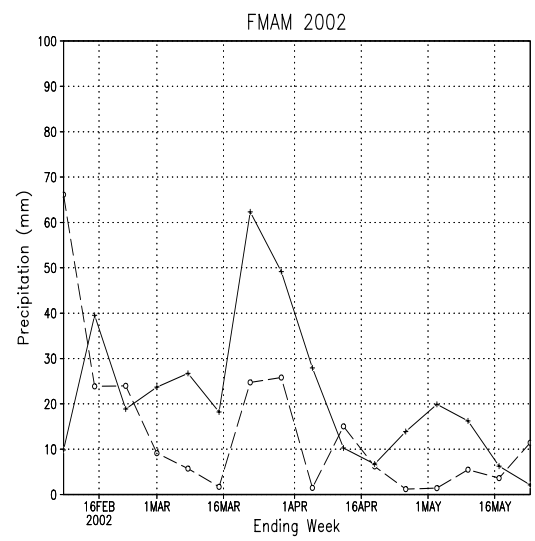

(c)

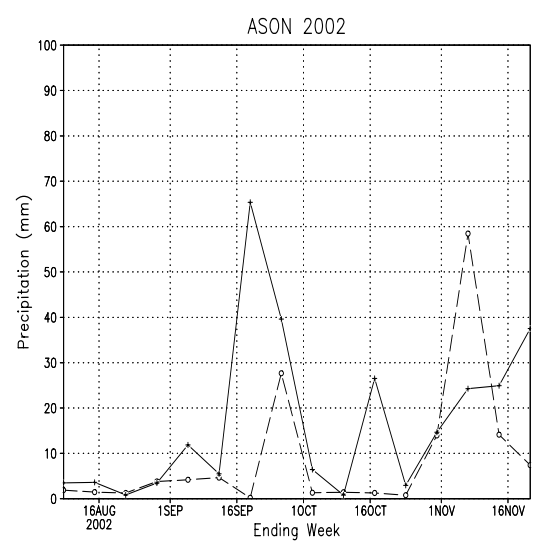

(b)

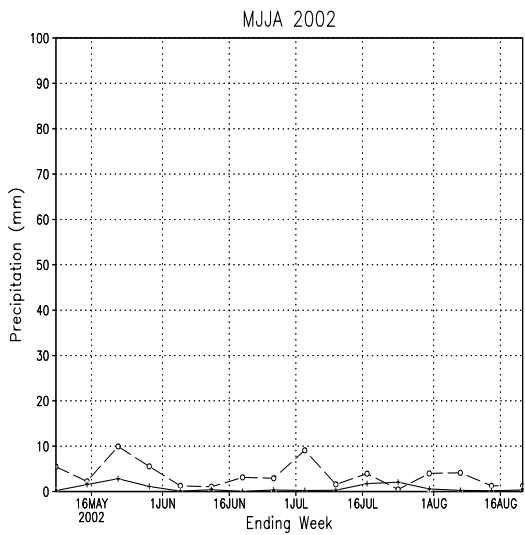

(d)

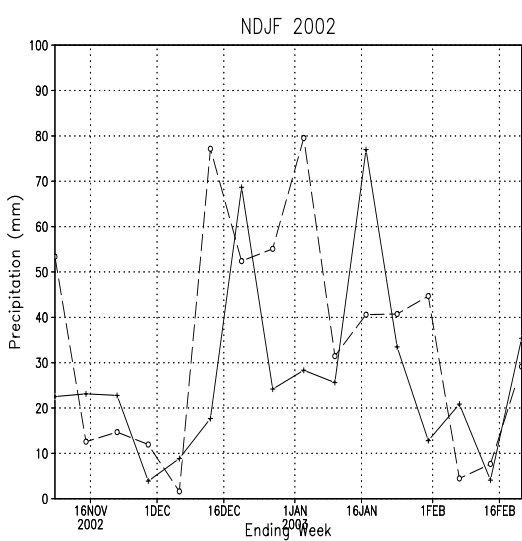

Fig. 19. Seasonal São Francisco Basin 7-day Mean Precipitation (mm) (a) FMAM, (b) MJJA, (c) ASON, and (d) NDJF. The dashed line is observation and solid line is Eta forecast.

Five-member ensemble runs were produced for the NDJF rainy season. Both driver model and Eta Model forecasts showed some internal variability in the SACZ and over the Andes regions.

Comparison of the regional model forecasts against climatology showed that in general the model produced additional useful information over the climatology, as the mean forecast errors were generally smaller than climatology errors.

An example of the transient variability related to the frontal systems was shown for the rainy season. The model gave some indication of the regime of the frontal disturbances along the coast in terms of frequency and movement.

The evaluation of weekly total precipitation was illustrated by application of these long-term forecasts to hydrological management of the the São Francisco Basin. The model showed difficulty in capturing weekly amount of seasonal predicted precipitation, although the sign of the tendency was indicated by positive correlations. The magnitude of the means and standard deviations were comparable to observations.

Although the results showed some similarities in the precipitation predictability behavior of the driver model and the Eta Model, the Eta improved considerably the forecasts from the driver model. In the current study, the Eta Model forecasts showed the highest skill in the Amazon region and the lowest skill in Northeast Brazil. The known higher predictability of the GCM forecasts over the Northeast of Brazil was based on the removal of model systematic error such as the assessment carried out by Cavalcanti et al. (2002). The regional model showed small bias, which could indicate small systematic error.

This one-year evaluation of seasonal precipitation forecasts also identified a number of issues related to the predictability. Some improvements may be sought by extending the ensemble forecast runs to different seasons and by applying some physics parameter adjustments. Integrations of the model for several different years can provide additional information on the model ability in capturing the inter-annual variability. These are further steps that can be taken after this initial evaluation.

Acknowledgements. The authors wish to thank F. Mesinger and A. Seth for useful comments on the text. The reviewers comments helped to improve the manuscript. This work was partly funded by CNPq under the process number 305.705/2002-0.

Edited by: S. Vannitsem

Reviewed by: F. Mesinger, A. Seth and another referee 


\section{References}

Bonatti, J. P.: Modelo de Circulação Geral Atmosférico do CPTEC, Climanálise. Special Edition, 1996.

Cavalcanti, I. F. A., Marengo, J. A., Satyamurty, P., et al.: Global climatological features in a simulation using the CPTEC-COLA AGCM, J. Climate, 15, 21, 2965-2988, 2002.

Chen, F., Janjić, Z. I., and Mitchell, K.: Impact of atmospheric surface-layer parameterization in the new land-surface scheme of the NCEP mesoscale Eta Model, Bound.-Layer Meteor., 85, 391-421, 1997.

Chou, S. C., Nunes, A. M. B., and Cavalcanti, I. F. A.: Extended range forecasts over South America using the regional Eta Model, J. Geophys. Res., 105, D8, 10 147-10 160, 2000.

Chou, S. C., Tanajura, C. A. S., Xue, Y., and Nobre, C. A.: Simulations with the Coupled Eta/SSiB Model over South America, J. Geophys. Res., 107, 20, 2003.

Climanálise: Boletim de Monitoramento e Análise Climática, Instituto Nacional de Pesquisas Espaciais, São José dos Campos, 17, 2, 2002.

Druyan, L. M., Fulakeza, M., and Lonergan, P.: Dynamic downscaling of seasonal climate predictions over Brazil, J. Climate, 15, 3411-3426, 2002.

Fels, S. B. and Schwarzkopf, M. D.: The simplified exchange approximation: A new method for radiative transfer calculations, J. Atmos. Sci., 32, 1475-1488, 1975.

Garstang, M., Massie, H. L. Jr., Halverson, J. et al.: Amazon Coastal Squall Lines, part I: Structure and kinematics, Mon. Wea. Rev., 122, 608-622, 1994.

Harshvardhan, D., Randall, A., and Corsett, T. G., A fast radiation parameterization for general circulation models, J. Geophys. Res., 92, 1009-1016, 1974.

Janjić, Z. I.: Forward-backward scheme modified to prevent twogrid-interval noise and its application in sigma coordinate models, Contrib. Atmos. Phys., 52, 69-84, 1979.

Janjić, Z. I.: The Step-mountain Eta Coordinate Model: Further Developments of the Convection, Viscous Sublayer and Turbulence Closure Schemes, Mon. Wea. Rev., 122, 927-945, 1994.

Kim, J., Miller, N. L., Farrara, J. D., and Hong, S. Y.: A seasonal and precipitation stream flow hindcast and prediction study for the 1997/1998 winter season using a dynamic downscaling system, J. Hydrometeorology, 1, 311-329, 2000.

Kyriakidis, P. C., Miller, N. L., and Kim, J.: Uncertainty propagation of regional climate model precipitation forecasts to hydrologic impact assessment, J. Hydrometeorology, 2, 140-160, 2001

Kuo, H. L.: Further Studies of the parameterization of the influence of cumulus convection on large-scale flow, J. Atmos. Sci., 31, 1232-1240, 1974.

Lacis, A. A. and Hansen, J. E.: A parameterization of the absorption of solar radiation in earth's atmosphere, J. Atmos. Sci., 31, 118 133,1974
Laprise, R., Varma, M. R., Denis, B. Caya, D., and Zawadzki, I.: Predictability of a nested limited-area model, Mon. Wea. Rev., 128, 4149-4154, 2000.

Mellor, G. L. and Yamada, T.: Development of a turbulence closure model for geophysical fluid problems, Rev. Geophys. Space Phys., 20, 851-875, 1982.

Mesinger, F.: An economical explicit scheme which inherently prevents the false two-grid-interval wave in the forecast fields, Symp. "Difference and Spectral Methods for Atmosphere and Ocean Dynamics Problems", Academy of Sciences, Novosibirsk 1973, Part II, 18-34, 1974.

Mesinger, F.: Forward-backward scheme and its use in a limited area model, Contrib. Atmos. Phys., 50, 200-210, 1977.

Mesinger, F.: A blocking technique for representation of mountains in atmospheric models, Rivista di Meteorologia Aeronautica, 44 $1-4,195-202,1984$.

Misra, V.: An evaluation of the Predictability of Austral Summer season Precipitation over South America, COLA Tech. Rep., 135, Calverton, MD., 2003.

Moura, A. D. and Shukla, J.: On the dynamics of droughts in Northeast Brazil: observations, theory and numerical experiments with a general circulation model, J. Atmos. Sci., 38, 2653-2765, 1986.

NMC Development Division Staff: Research version of the medium range forecast model, NMC Documentation Series 1, Available from the development Division, NCEP, Washington, DC 20233, 399, 1988.

Nobre, P., Moura, A. D., and Sun, L.: Dynamical downscaling of seasonal climate prediction over Nordeste brazil with ECHAM3 and NCEP's Regional Spectral Models at IRI, Bull. Amer. Meteor. Soc.. 82, 12, 2787-2796, 2001.

Palmer, T. N., Branković, C., Molteni, F., and Moreau, R.: Predictability in the medium range and beyond, Proceedings of the ECMWF Seminar "Ten years of medium-range weather forecasting” Reading, UK, 4-8 September 1989, 129-158, 1990.

Rudolf, B., Fuchs, T., Schneider, U., and Meyer-Christopher, A.: GPCC Introduction, Deutscher Wetterdienst, Germany, http://www.dwd.de/en/FundE/Klima/KLIS/int/GPCC/ Reports_Publications/QR/GPCC_Introduction.pdf, 2003.

Xie, P. E. and Arkin, P. A.: Global precipitation: A 17-year monthly analysis based on gauge observations, satellite estimates, and numerical model outputs, Bull. Amer. Meteor. Soc., 78, 25392558, 1997.

Xue, Y., Sellers, P. J., Kinter III, J. L., and Shukla, J.: A simplified biosphere model for global climate studies, J. Climate, 4, 345364, 1991.

Zhao, Q. and Carr, F. H.: A prognostic cloud scheme for operational NWP Models, Mon. Wea. Rev., 125, 1931-1953, 1997. 